\title{
Spontaneous Release Regulates Synaptic Scaling in the Embryonic Spinal Network In Vivo
}

\author{
Miguel Angel Garcia-Bereguiain, ${ }^{1,2 *} \mathbb{C}$ Carlos Gonzalez-Islas, ${ }^{1,3 *}$ Casie Lindsly, ${ }^{1}$ and $\odot$ Peter Wenner ${ }^{1}$ \\ ${ }^{1}$ Department of Physiology, Emory University School of Medicine, Atlanta, Georgia 30322, ${ }^{2}$ Laboratorio de Biomedicina, Facultad de Ciencias de la Vida \\ Escuela Superior Politécnica del Litoral, Guayaquil, Ecuador, and ${ }^{3}$ Doctorado en Ciencias Biológicas Universidad Autónoma de Tlaxcala, Tlaxcala 90062, \\ Mexico
}

Homeostatic plasticity mechanisms maintain cellular or network spiking activity within a physiologically functional range through compensatory changes in synaptic strength or intrinsic cellular excitability. Synaptic scaling is one form of homeostatic plasticity that is triggered after blockade of spiking or neurotransmission in which the strengths of all synaptic inputs to a cell are multiplicatively scaled upward or downward in a compensatory fashion. We have shown previously that synaptic upscaling could be triggered in chick embryo spinal motoneurons by complete blockade of spiking or $G A B A_{A}$ receptor $\left(G A B A_{A} R\right)$ activation for $2 d$ in vivo. Here, we alter $G A B A_{A} R$ activation in a more physiologically relevant manner by chronically adjusting presynaptic GABA release in vivo using nicotinic modulators or an mGluR2 agonist. Manipulating $\mathrm{GABA}_{\mathrm{A}} \mathrm{R}$ activation in this way triggered scaling in a mechanistically similar manner to scaling induced by complete blockade of $\mathrm{GABA}_{\mathrm{A}}$ Rs. Remarkably, we find that altering action-potential (AP)-independent spontaneous release was able to fully account for the observed bidirectional scaling, whereas dramatic changes in spiking activity associated with spontaneous network activity had little effect on quantal amplitude. The reliance of scaling on an AP-independent process challenges the plasticity's relatedness to spiking in the living embryonic spinal network. Our findings have implications for the trigger and function of synaptic scaling and suggest that spontaneous release functions to regulate synaptic strength homeostatically in vivo.

Key words: chick embryo; homeostatic plasticity; nicotine; spinal cord; spontaneous release; synaptic scaling

\section{Significance Statement}

Homeostatic synaptic scaling is thought to prevent inappropriate levels of spiking activity through compensatory adjustments in the strength of synaptic inputs. Therefore, it is thought that perturbations in spike rate trigger scaling. Here, we find that dramatic changes in spiking activity in the embryonic spinal cord have little effect on synaptic scaling; conversely, alterations in $\mathrm{GABA}_{\mathrm{A}}$ receptor activation due to action-potential-independent GABA vesicle release can trigger scaling. The findings suggest that scaling in the living embryonic spinal cord functions to maintain synaptic strength and challenge the view that scaling acts to regulate spiking activity homeostatically. Finally, the results indicate that fetal exposure to drugs that influence GABA spontaneous release, such as nicotine, could profoundly affect synaptic maturation.

\section{Introduction}

Homeostatic plasticity is thought to maintain network activity levels through compensatory adjustments in cellular excitability and synaptic strength (Desai, 2003; Marder and Goaillard, 2006;

Received Nov. 11, 2015; revised May 25, 2016; accepted May 26, 2016.

Author contributions: M.A.G.-B., C.G.-I., C.L., and P.W. designed research; M.A.G.-B., C.G.-I., C.L., and P.W. performed research; M.A.G.-B., C.G.-I., C.L., and P.W. analyzed data; M.A.G.-B., C.G.-I., C.L., and P.W. wrote the paper.

This work was supported by grants from the National Institute of Neurological Disorders and Stroke and the Whitehall Foundation to P.W. We thank Drs. Mark Rich and Astrid Prinz for valuable comments on the manuscript. The authors declare no competing financial interests.

${ }^{*}$ M.A.G.-B. and C.G.-I. contributed equally to this work.

Correspondence should be addressed to Peter Wenner, Department of Physiology, Room 601 Whitehead Bldg., Emory University School of Medicine, Atlanta, GA 30322. E-mail: pwenner@emory.edu.

DOI:10.1523/JNEUROSCI.4066-15.2016

Copyright $\odot 2016$ the authors $\quad 0270-6474 / 16 / 367268-15 \$ 15.00 / 0$
Turrigiano, 2011; Davis, 2013). The most studied form of homeostatic plasticity has been called synaptic scaling, in which compensatory changes in synaptic strength are observed after perturbations in spiking activity for many hours (Turrigiano et al., 1998; Turrigiano, 2012). For instance, when spiking was blocked for $2 \mathrm{~d}$ in cortical neuronal cultures, AMPAergic synaptic strength increased (Turrigiano et al., 1998). In addition, blockade of glutamatergic receptor activation can also trigger compensatory increases in synaptic strength (O'Brien et al., 1998; Thiagarajan et al., 2005; Stellwagen and Malenka, 2006; Fong et al., 2015). These compensatory changes occur across the entire distribution of the cell's miniature postsynaptic current (mPSC) amplitudes by a multiplicative scaling factor. Scaling is typically observed and studied in vitro, but has been described to a lesser extent in vivo in the spinal cord (Gonzalez-Islas and Wenner, 
2006; Knogler et al., 2010; Wenner, 2014) and visual system (Desai et al., 2002; Goel et al., 2006; Whitt et al., 2014).

Studies of synaptic scaling are now focused on the molecular mechanisms that underlie the plasticity. The most critical component of the signaling cascade mediating synaptic scaling is the initiating factor or trigger for this form of plasticity (Rich and Wenner, 2007). Identification of the triggering signals will be crucial for understanding the function of scaling, but will also help us predict when compensatory changes in synaptic strength occur after changes to the network (development, as a response to injury or in disease, or after drug exposure). Unfortunately, identifying the triggers has been elusive because the kind of perturbations that are used to trigger scaling typically influence multiple factors coordinately, including spike rate, neurotransmission, and network activity and any associated signaling cascades (Rich and Wenner, 2007; Lee et al., 2014).

In the current study, we focused on identifying triggers of synaptic scaling that occur in the living embryonic spinal cord. Developing neural circuits display episodic patterned spontaneous network activity (SNA). This activity is generated by a recurrently connected network critically dependent on GABA- and glutamate-mediated neurotransmission, which are both excitatory in early development (O'Donovan, 1999; Ben-Ari, 2001; Blankenship and Feller, 2010). We have demonstrated previously that blocking SNA-generated embryonic movements for $2 \mathrm{~d}$ in the living chick embryo triggered upscaling of both glutamatergic and depolarizing GABAergic currents as assessed in the isolated cord (Gonzalez-Islas and Wenner, 2006). We were then able to show that upscaling could be triggered by blocking $\mathrm{GABA}_{\mathrm{A}} \mathrm{Rs}$, which only transiently reduced embryonic movements before they homeostatically recovered several hours after antagonist injection (Wilhelm and Wenner, 2008). We interpreted these results in the following manner: reductions in spiking associated with SNA led to a significant reduction in the action potential (AP)-dependent release of GABA and this reduced the activation of $\mathrm{GABA}_{\mathrm{A}}$ receptors $\left(\mathrm{GABA}_{\mathrm{A}} \mathrm{Rs}\right)$, which triggered upscaling. The idea was that GABA was a proxy for SNA levels.

Here, we better define the nature of $\mathrm{GABA}_{\mathrm{A}} \mathrm{R}$ activation that influences scaling by presynaptically altering GABA vesicle release through in ovo injections of nicotinic receptor (nAChR) modulators (Gonzalez-Islas et al., 2016) or a group II metabotropic glutamate receptor (mGluR2) agonist. Confirming our idea that $G_{A B A} R$ activation is key to triggering scaling, we found that inhibiting GABA vesicle release triggered upscaling and show that enhancing GABA release triggered downscaling. Conversely, our results refute our original idea that $G_{A B A} R$ activation associated with SNA was important for scaling. Rather, we find that altering AP-independent spontaneous GABA release alone could fully account for scaling observed in this system. The results highlight the importance of $\mathrm{GABA}_{\mathrm{A}} \mathrm{R}$ activation due to spontaneous release and challenge the idea that scaling is functionally tied to spiking in the embryonic spinal cord in vivo.

\section{Materials and Methods}

Dissection. Eggs (chick embryos of either sex) were placed in a 1550 Digital Hatcher incubator (GQF Manufacturing) for 8-10 d [embryonic days 8-10 (E8-E10), stages 34-36 (Hamburger and Hamilton, 1951)] at $38^{\circ} \mathrm{C}$. The lumbosacral spinal cord with attached spinal nerves was isolated under cooled $\left(15^{\circ} \mathrm{C}\right)$ oxygenated Tyrode's solution containing the following (in mM): $139 \mathrm{NaCl}, 12$ D-glucose, $17 \mathrm{NaHCO}_{3}, 3 \mathrm{KCl}, 1 \mathrm{MgCl}_{2}$, and $3 \mathrm{CaCl}_{2}$. Tyrode's solution was constantly bubbled with a mixture of $95 \% \mathrm{O}_{2} / 5 \% \mathrm{CO}_{2}$ to maintain $\mathrm{pH}$ at $\sim 7.3$. After dissection, the cord was allowed to recover for at least $6 \mathrm{~h}$ in Tyrode's solution at $18^{\circ} \mathrm{C}$. The cord was then transferred to a recording chamber and continuously perfused with oxygenated Tyrode's solution that was slowly heated to recording temperature $\left(28^{\circ} \mathrm{C}\right)$. Stable episodes of SNA (constant burst frequency, every $8-10 \mathrm{~min}$ ) were established before starting the experiments.

Transfections (in ovo electroporations) and Clomeleon imaging. On E3 (stages 16-18; Hamburger and Hamilton, 1951), a small window was cut into the shell of white leghorn chicken eggs (Hy-line) and plasmids coding for the Clomeleon protein under control of a CMV promoter (kind gift of George Augustine) were injected into the central canal of the neural tube. Two electrodes spaced $4 \mathrm{~mm}$ apart were lowered onto the chorioallantoic membrane on either side of the embryo and 5 pulses ( 25 $\mathrm{V}, 50 \mathrm{~ms}$, interval of $1 \mathrm{~s}$ ) were delivered using an ECM 830 electroporator (Lindsly et al., 2014).

Isolated E10 spinal cords were placed ventral side down in the recording chamber of an Olympus IX70 inverted microscope and continuously perfused with Tyrode's solution. The solution was heated to $27^{\circ} \mathrm{C}$ and transfected neurons were imaged through the ventral white matter using a $10 \times$ objective. Clomeleon is a fusion protein containing 2 fluorophores, the $\mathrm{Cl}^{-}$-insensitive cyan fluorescent protein (CFP) and the $\mathrm{Cl}^{-}$sensitive yellow fluorescent protein (YFP) (Kuner and Augustine, 2000). Illumination results in excitation of CFP $(430-450 \mathrm{~nm})$, producing emission at $485 \mathrm{~nm}$, which excites the YFP fluorophore through fluorescence resonance energy transfer (FRET). Therefore, emitted light was passed through a dichroic mirror with a $460 \mathrm{~nm}$ cutoff and then filtered through emission filters for CFP $(485 \pm 15 \mathrm{~nm})$ or YFP $(530 \pm 15 \mathrm{~nm})$. To limit differential photobleaching of the Clomeleon fluorophores, we used neutral density filters so that only $1.5 \%$ of light reached the specimen. In addition, we limited exposure time $(200 \mathrm{~ms})$ using a uniblitz shutter (Vincent Associates). The emission for each fluorophore was then captured onto an intensified CCD camera (Stanford Photonics) and images were recorded using SimplePCI software (Hamamatsu) as a 20frame average. Images were then processed in SimplePCI by measuring the mean intensity of a region of interest (ROI) drawn around a cell body and subtracting the mean intensity for a background ROI located in a nonlabeled part of the cord. This process was conducted for both CFP and YFP images and the resulting values were expressed as a ratio (YFP/CFP) for each cell. Because Clomeleon is sensitive to internal $\mathrm{pH}$, we monitored and maintained the $\mathrm{pH}$ of the bath at 7.2-7.3 during recordings.

Clomeleon ratios were calibrated based on our previous study (for a complete description, see Lindsly et al., 2014). We measured the FRET ratios in the following solutions: $150 \mathrm{mM} \mathrm{Cl}^{-}, 75 \mathrm{~mm} \mathrm{Cl}^{-}, 50 \mathrm{mM} \mathrm{Cl}^{-}, 30$ $\mathrm{mM} \mathrm{Cl}^{-}$(chloride and gluconate concentrations summed to $150 \mathrm{~mm}$ ). All calibration solutions contained $10 \mu \mathrm{M}$ nigericin $\left(\mathrm{K}^{+} / \mathrm{H}^{+}\right.$ionophore) and $100 \mu \mathrm{M}$ tributyltin chloride $\left(\mathrm{Cl}^{-} / \mathrm{OH}^{-}\right.$antiporter $)$to remove transmembrane $\mathrm{H}^{+} / \mathrm{OH}^{-}$and $\mathrm{Cl}^{-}$gradients (Berglund et al., 2006). The dissociation constant $\left(K_{\mathrm{D}}\right)$ and $R_{\max }$ (value for Clomeleon completely unbound by $\mathrm{Cl}^{-}$) were determined from a nonlinear regression of the average ratios to $\left[\mathrm{Cl}^{-}\right]$using the following equation: $r=\left[\left(\mathrm{K}_{\mathrm{D}} * \mathrm{R}_{\max }\right)+\right.$ $\left.\left(\left[\mathrm{Cl}^{-}\right] * \mathrm{R}_{\min }\right)\right] /\left(\left[\mathrm{Cl}^{-}\right]+R_{\min }\right)$ (Dzhala et al., 2012). $R_{\max }$ could not be evaluated from a $0 \mathrm{~mm} \mathrm{Cl}^{-}$calibration solution as ratio values dropped and did not recover in other calibration solutions. The $R_{\min }$ (value for Clomeleon completely bound by $\mathrm{Cl}^{-}$) was determined from ratios measured in a $\mathrm{KF}$ solution as $\mathrm{F}^{-}$is known to saturate the YFP moiety. As described previously (Lindsly et al., 2014), in 5 spinal cords we found, $R_{\text {min }}=0.53 \pm 0.01, K_{\mathrm{D}}=91.6 \pm 27.0$, and $R_{\max }=2.7 \pm 0.28$. These values were used for conversion of ratios to $\mathrm{CI}_{\text {in }}^{-}$using the following formula: $\mathrm{CI}_{\mathrm{in}}^{-}=K_{\mathrm{D}}\left(R_{\max }-R\right) /\left(R-R_{\min }\right)$ (Berglund et al., 2006; Pond et al., 2006; Dzhala et al., 2012).

Electrophysiology. Experiments were performed on E8-E10 white Leghorn chicken embryos. Tight-fitting glass suction electrodes were used to record from the ventrolateral funiculus (VLF). For monitoring SNA, VLF signals were amplified $(1000 \times)$, filtered $(0.1 \mathrm{~Hz}$ to 1 $\mathrm{kHz}$ ) by an extracellular amplifier (A-M Systems), and acquired using PClamp 10 (Molecular Devices). Analyses of the data were performed offline. 
Whole-cell patch-clamp recordings were made from motoneurons localized between lumbosacral segments 1 and 3 and were identified by their lateral position in the ventral cord. Motoneurons were held at $-70 \mathrm{mV}$ to acquire mPSCs (TTX, $0.5 \mu \mathrm{M}$ added to bath). Tyrode's solution was used as the extracellular recording solution and mPSC patch solution contained the following (in $\mathrm{mM}$ ): $5 \mathrm{NaCl}, 100$ K-gluconate, $36 \mathrm{KCl}, 10 \mathrm{HEPES}, 1.1 \mathrm{EGTA}, 1 \mathrm{MgCl}_{2}, 0.1 \mathrm{CaCl}_{2}, 1$ $\mathrm{Na}_{2}$ ATP, and 0.1 MgGTP; $\mathrm{pH}$ adjusted to 7.3 with KOH. Patch-clamp tight seals $(>2 \mathrm{G} \Omega$ ) were obtained using electrodes pulled from thinwalled glass (World Precision Instruments) using a micropipette puller (Sutter Instruments) to obtain resistances between 5 and 10 $\mathrm{M} \Omega$. Recordings were terminated whenever significant increases in series resistance $(>20 \%)$ occurred. AMPA and GABA mPSCs were separated by their decay kinetics (AMPA $\tau \leq 6.0 \mathrm{~ms}$, GABA $\tau \geq 7.0$ $\mathrm{ms}$, values between 6.0 and $7.0 \mathrm{~ms}$ were not included in the analysis) as described previously (Gonzalez-Islas and Wenner, 2006). The mPSCs were acquired on an Axopatch 200B patch clamp amplifier (Molecular Devices), digitized online using PClamp 10 (Molecular Devices), and analyzed using Minianalysis software (Synaptosoft). Bar charts and associated average values were obtained by determining an average mPSC amplitude for each cell (variable number of $\mathrm{mPSCs} /$ cell, $5 \mathrm{pA}$ cutoff) and then calculating the average of all cells. To approximate whether mPSC cumulative amplitude distributions from treated embryos were multiplicatively related to control distributions ("scaled"), it was necessary to account for mPSC amplitudes that fell into the noise after different treatments (particularly AMPA mPSCs; Garcia-Bereguiain et al., 2013). Therefore, the following steps were taken: cumulative probability distributions were obtained by combining mPSC amplitudes in control or different treatments (30 mPSCs per cell or, in some cases, 50 mPSCs per cell as in Figs. 3, 9). We multiplied the distribution with the largest amplitudes by a factor of $<1$, then removed values that fell below the 5 pA cutoff and compared the distributions using a Kolmogorov-Smirnov test. For example, all GABA mPSC amplitudes from $\mathrm{Dh} \beta \mathrm{E}$-treated motoneurons were multiplied by 0.65 , values that fell below 5 pA were removed, and the downscaled distribution was compared with the distribution of GABA mPSC amplitudes from control motoneurons using the Kolmogorov-Smirnov test.

In ovo drug application and movement counts. Windows in the shell of the egg were opened at E8 and lidocaine hydrochloride aqueous solution ( $35 \mathrm{mg} / \mathrm{ml}$ plus $10 \mathrm{~mm}$ HEPES, pH 7.2) was continuously infused onto the chorioallantoic membrane of the embryos at a rate of $13.5 \mu \mathrm{l} / \mathrm{h}$, as described previously (Gonzalez-Islas and Wenner, 2006). For other drug applications, a single bolus of the drug was delivered onto the chorioallantoic membrane of the embryo at E8 to reach a particular concentration in the egg, assuming a $50 \mathrm{ml}$ volume (Wilhelm and Wenner, 2008) containing gabazine $(10 \mu \mathrm{M})$, nicotine $(10 \mu \mathrm{M})$, dihydro- $\beta$-erythroidine hydrobromide (DH $\beta \mathrm{E}, 5 \mu \mathrm{M})$, and $\left.2 S, 2^{\prime} R, 3^{\prime} R\right)-2-\left(2^{\prime}, 3^{\prime}\right.$-dicarboxycyclopropyl)glycine (DCG-IV, $2 \mu \mathrm{M}$ ). Embryonic movements were assessed through the window in the shell of the egg. Total duration of movements was monitored during 5 min observation periods taken regularly from E8 to E9 or E10.

Drugs. Nicotine, DH $\beta$ E, DCG-IV, lidocaine hydrochloride, and gabazine were purchased from Tocris Bioscience.

Statistics. Data are expressed as mean \pm SE. For normally distributed data, we used a two-tailed Student's $t$ test or one-way ANOVA with post hoc Tukey test for multiple comparisons (Kaleidagraph). For data that were not normally distributed, we ran Kruskal-Wallis nonparametric test with Conover-Iman procedure for multiple comparisons (XLSTAT; Microsoft). Best-fit analyses were performed for cumulative distributions using a Kolmogorov-Smirnov test $(\alpha=0.05)$ with XLSTAT. Throughout the study, we identify significantly different results as ${ }^{*} p<$ $0.05,{ }^{* *} p<0.01$, or ${ }^{* * *} p<0.001$.

\section{Results}

Homeostatic regulation of embryonic movements after in ovo injection of nicotinic modulators

Recently, we demonstrated that nicotine increased and the nicotinic antagonist $\mathrm{DH} \beta \mathrm{E}$ decreased GABAergic mPSC frequency and evoked GABAergic responses presynaptically in the embryonic spinal cord (Gonzalez-Islas et al., 2016). In contrast, the nicotinic modulators did not appear to have any direct postsynaptic effect. Furthermore, we showed that altering GABA release with these nicotinic modulators also influenced the frequency of SNA in the isolated spinal cord preparation. Nicotine initially blocked the expression of SNA, which likely resulted due to inhibition of the Renshaw pathway (Gonzalez-Islas et al., 2016). SNA then returned at a frequency that was higher than before nicotine application. Conversely, nicotinic antagonists resulted in a reduced SNA frequency in the isolated preparation. To determine whether nicotinic modulators had similar effects on SNA in the living embryo, we made in vivo injections with concentrations of drugs that were comparable to those used in vitro (assuming 50 $\mathrm{ml}$ egg volume). We assessed SNA in vivo by determining the duration of spinally generated embryonic movements in $5 \mathrm{~min}$ observation periods starting at the time of injection at $\mathrm{E} 8$ until E10. When we injected $\mathrm{DH} \beta \mathrm{E}(5 \mu \mathrm{M})$, we found that this significantly reduced embryonic movements, which homeostatically recovered $4 \mathrm{~h}$ after adding the drug and largely followed control levels through E10 (Fig. 1A). After in ovo injection of nicotine $(10 \mu \mathrm{M})$, embryonic movement duration was initially reduced, but $6 \mathrm{~h}$ after injection, movement duration was elevated compared with controls; movements then homeostatically recovered to control levels $32 \mathrm{~h}$ after nicotine injection (Fig. $1 \mathrm{~A}$ ). The results suggested that the nicotinic modulators had similar effects on SNA in vitro and in vivo, although the duration of drug effect was different (Gonzalez-Islas et al., 2016).

To assess the effect of nicotinic modulators on the excitability of the spinal cord after chronic drug treatment (E8-E10), spinal cords were isolated and maintained in recirculating Tyrode's solution in the absence of nicotine receptor modulators. As shown in Figure 1B, the frequency of SNA was no different in spinal cords isolated from control embryos, nicotine-treated embryos, or DH $\beta$ E-treated embryos. These results suggest that chronic nicotinic modulator treatment did not produce sustained changes in spinal excitability.

\section{Nicotinic modulators induced synaptic scaling in vivo}

We have shown previously that complete blockade of $\mathrm{GABA}_{\mathrm{A}} \mathrm{R}$ activation triggers upscaling of AMPA and GABA mPSCs (Wilhelm, 2008). To determine whether scaling could be triggered by simply altering GABA vesicle release presynaptically, we treated embryos from E8 to E10 with nicotinic modulators as described above. We tested whether decreasing $\mathrm{GABA}_{\mathrm{A}} \mathrm{R}$ activation by chronic DH $\beta$ E treatment would cause an upscaling. After $2 \mathrm{~d}$ of treatments (E8-E10), we isolated the spinal cord and made whole-cell measurements of mPSCs from spinal motoneurons. AMPA and GABA mPSCs were kinetically isolated from the same set of motoneurons (Gonzalez-Islas and Wenner, 2006). We found that $2 \mathrm{~d}$ of $\mathrm{DH} \beta \mathrm{E}$ treatment resulted in an increase of both AMPAergic and GABAergic mPSC amplitude compared with controls (Fig. 2, Table 1). Moreover, mPSC amplitudes from $\mathrm{DH} \beta \mathrm{E}$-treated embryos demonstrated the characteristic scaling profile, such that amplitudes were upscaled across their distribution by a multiplicative factor (Fig. 2C,D).

Because decreasing nAChR activation caused upscaling, we hypothesized that increasing $\mathrm{nAChR}$ activation and therefore GABA release could cause downscaling by chronically increasing $\mathrm{GABA}_{\mathrm{A}} \mathrm{R}$ activation. We treated embryos with nicotine to increase GABA release from E8 to E10 and measured mPSCs at E10. We found that chronic nicotine treatment caused a decrease of 

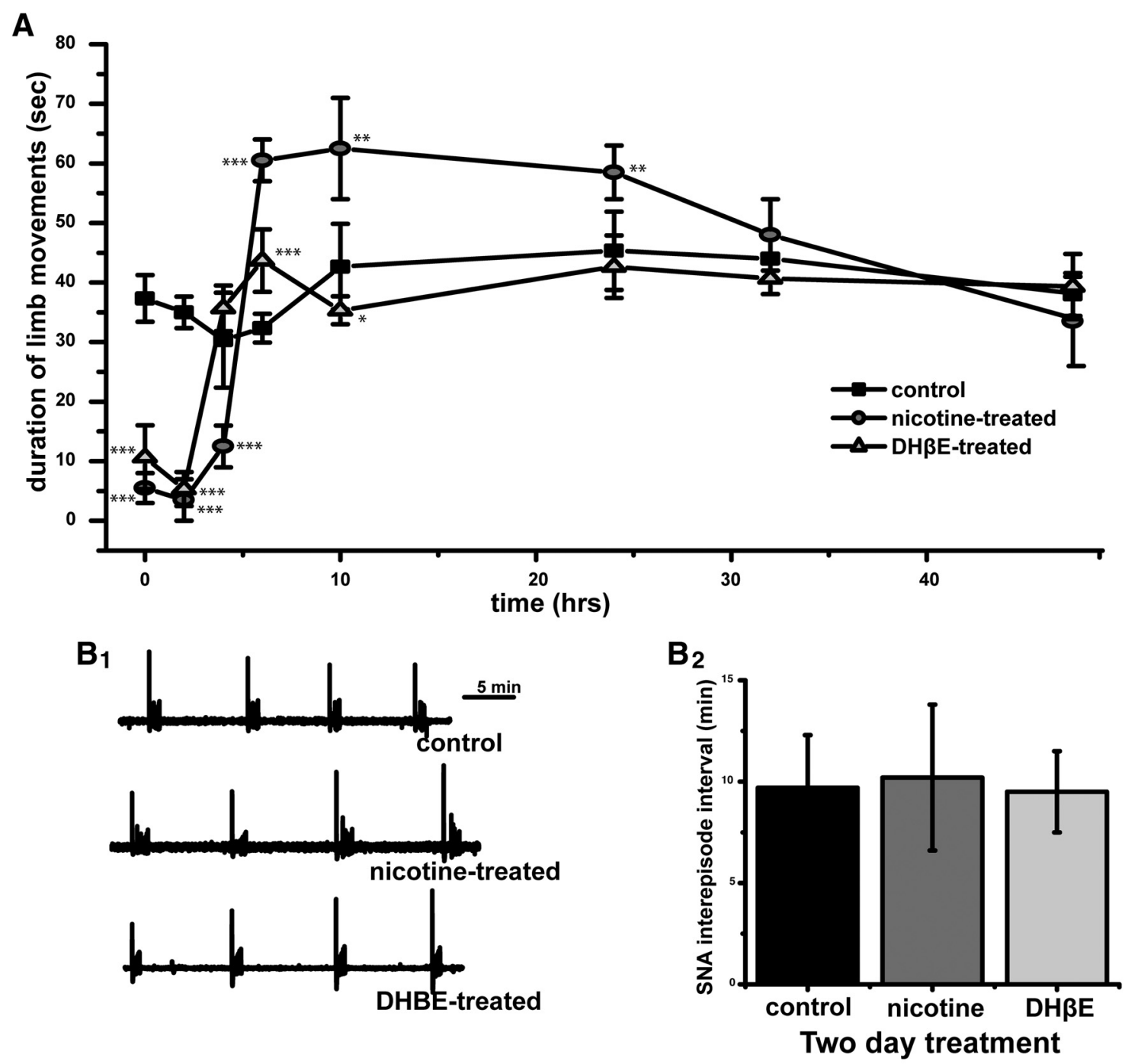

\section{SNA of isolated cords}

Figure 1. Nicotinic modulation of SNA. $A$, Graph of the average duration of chick embryo movements in a 5 min observation window from E8 to E10 (control, $n=7 ;$ nicotine, $10 \mu \mathrm{M}$ $n=6 ; \mathrm{DH} \beta \mathrm{E}, 5 \mu \mathrm{m} ; n=7)$. Kicking duration significantly different from control values are indicated $\left({ }^{*} p<0.05,{ }^{* *} p<0.01,{ }^{* * *} p<0.001\right)$. B, Spinal cords were isolated in drug-free solution and SNA was monitored by VLF recordings. $\boldsymbol{B 1}$, Representative traces showing SNA in cords isolated from embryos that received different $2 \mathrm{~d}$ treatments. $\boldsymbol{B 2}$, Average values for SNA frequency in isolated cords. The frequency of SNA was no different in spinal cords isolated from control embryos $(9.8 \pm 1.2 \mathrm{~min}, n=6)$, nicotine-treated embryos $(9.6 \pm 1.8$ min, $n=4)$, or $\mathrm{DH} \beta \mathrm{E}$-treated embryos (10 $\mu \mathrm{m}, 10.2 \pm 1.1 \mathrm{~min}, n=4)$. Error bars represent SE; Kruskal-Wallis nonparametric test with Conover-Iman procedure for multiple comparisons.

AMPAergic and GABAergic mPSC amplitude (Fig. 3, Table 1). Further, AMPAergic and GABAergic mPSCs were multiplicatively scaled downward (Fig. 3C,D). No significant differences were found in the frequency of mPSCs for any of the treatments (Table 1). The results suggested the possibility that inhibiting or enhancing $\mathrm{nAChR}$ activation could trigger upscaling or downscaling, respectively.

In our previous study (Gonzalez-Islas et al., 2016), we had shown that nicotine acted presynaptically to enhance GABA release at E10. To confirm that nicotinic modulation was altering GABA release in the E8 embryo, we performed the following experiments. We isolated spinal cords from E8 embryos and superfused Tyrode's solution with or without nicotine for at least $6 \mathrm{~h}$. We then recorded from motoneurons and found that $6 \mathrm{~h}$ of nicotine treatment caused a sustained increase of GABA mPSC frequency, but not amplitude (Fig. $4 A, B)$. In addition, we wanted to determine whether the in- crease in GABAergic mPSC frequency was maintained in vivo. Therefore, we treated embryos at E8 for $12 \mathrm{~h}$ with either saline or nicotine $(10 \mu \mathrm{M})$. We then isolated spinal preparations and allowed them to recover overnight (nicotine-treated cords were isolated and maintained in nicotine-containing Tyrode's solution) and made whole-cell recordings from motoneurons the next day (spinal cords from nicotine-treated embryos were recorded in the continued presence of nicotine). We found that GABAergic mPSC frequency was still increased compared with controls (Fig. 4C). Interestingly, AMPAergic mPSC amplitude decreased after just $12 \mathrm{~h}$ of in ovo nicotine treatment, whereas GABAergic mPSC amplitude trended downward but did not reach significance (Fig. 4D). This suggested that downscaling could occur in as little as $12 \mathrm{~h}$, as opposed to upscaling, which takes $>12 \mathrm{~h}$ of $\mathrm{GABA}_{\mathrm{A}} \mathrm{R}$ perturbation. Together, these results suggested that nicotinic modulators altered GABA release in ovo and triggered synaptic scaling. 
A

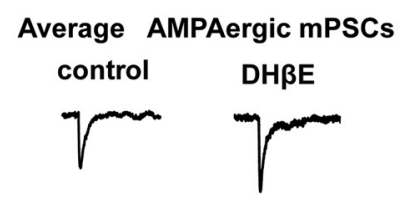

Average GABAergic mPSCs

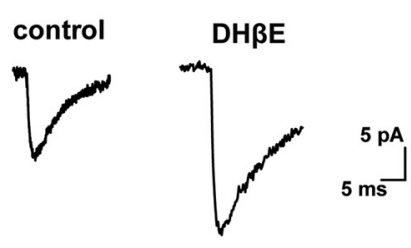

C

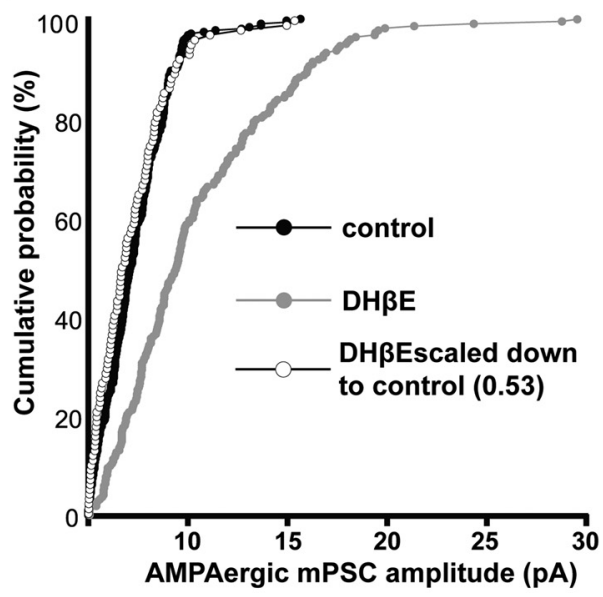

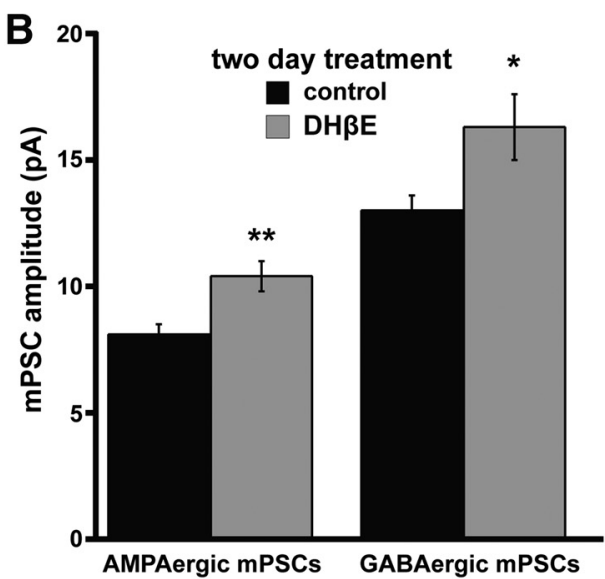

D

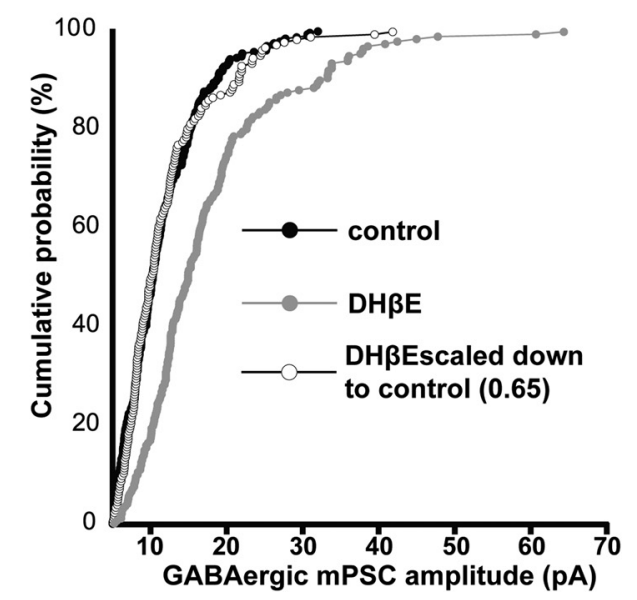

Figure 2. In ovo chronic $\mathrm{DH} \beta \mathrm{E}$ treatment triggers AMPAergic and GABAergic synaptic upscaling. $A$, Representative single-cell averages of control AMPA or GABA mPSCs or after DH $\beta \mathrm{E}$ treatment (E8-E10). $B$, Bar chart showing average values of AMPAergic or GABAergic mPSC amplitude for control embryos or those chronically treated with DH $\beta E$ (5 $\mu \mathrm{M})$. Error bars represent SE and significantly different values are indicated $\left({ }^{*} p<0.05,{ }^{* *} p<0.01\right)$. C, Cumulative probability plots for AMPAergic mPSC amplitudes (control embryos, $n=7$; $\mathrm{DH} \beta \mathrm{E}$-treated embryos, $n=8$ ). Amplitudes were shifted to the right after $\mathrm{Dh} \beta \mathrm{E}$ treatment and demonstrated the scaling profile (as shown by plotting the scaled Dh $\beta \mathrm{E}$ distribution multiplied by 0.53 and removing values that fell below $5 \mathrm{pA}$ ). $\boldsymbol{D}$, Cumulative probability plots for GABAergic mPSC amplitudes (control embryos, $n=7$; $\mathrm{DH} \beta \mathrm{E}$-treated embryos, $n=7$ ). Amplitudes were shifted to the right after $\mathrm{Dh} \beta \mathrm{E}$ treatment and demonstrated the scaling profile (as shown by plotting the scaled Dh $\beta \mathrm{E}$ distribution multiplied by 0.65 and removing values that fell below $5 \mathrm{pA}$ ).

GABAergic scaling was mediated by changes in intracellular chloride

We demonstrated previously that GABAergic upscaling was mediated by increases in intracellular chloride $\left(\mathrm{CI}_{\text {in }}^{-}\right.$, from $\sim 50$ to $\sim 85 \mathrm{~mm}$ ) after complete $\mathrm{GABA}_{\mathrm{A}} \mathrm{R}$ blockade (gabazine injection) or spike blockade (lidocaine infusion) (GonzalezIslas et al., 2010; Lindsly et al., 2014). Therefore, we tested whether GABAergic upscaling occurred through the same process after $\mathrm{Dh} \beta \mathrm{E}$-mediated reductions in GABA release. We assessed motoneuron $\mathrm{CI}_{\text {in }}^{-}$after $\mathrm{Dh} \beta \mathrm{E}$ treatment using the ratiometric chloride indicator Clomeleon, as we had done previously (Lindsly et al., 2014). Clomeleon is a fusion protein of CFP (chloride-insensitive) and YFP (chloride-sensitive) and is electroporated into spinal neurons at E3 (Fig. 5). We assessed the ratio of YFP to CFP for ROIs drawn around labeled motoneurons at E10 to approximate $\mathrm{CI}_{\text {in }}^{-}$(Fig. $5 C$; see Materials and Methods). After Dh $\beta$ E treatment from E8 to E10, motoneuron Clomeleon ratios were altered (Fig. 5D) similar to that described after spike or $\mathrm{GABA}_{\mathrm{A}}$ receptor blockade (Lindsly et al., 2014). The results support the idea that the scaling mechanisms are similar after blockade of nicotinic receptors, $\mathrm{GABA}_{\mathrm{A}}$ receptors, and spiking.

The mechanism of GABAergic downscaling is unknown. Therefore, we treated embryos with nicotine from E8 to E10 to trigger GABAergic downscaling and assessed motoneuron $\mathrm{CI}_{\text {in }}^{-}$ using Clomeleon. We found that GABAergic downscaling led to changes in Clomeleon ratios that were consistent with a reduction in $\mathrm{CI}_{\text {in }}^{-}$(Fig. 5).

Synaptic scaling induced by nicotine receptor modulators were dependent on $\mathrm{GABA}_{\mathrm{A}}$ receptor activation

The above results were consistent with the idea that in ovo treatment with nicotine or $\mathrm{DH} \beta \mathrm{E}$ altered GABA vesicle release and therefore $\mathrm{GABA}_{\mathrm{A}} \mathrm{R}$ activation and in this way triggered scaling. If nicotinic modulators triggered scaling through activation of the $\mathrm{GABA}_{\mathrm{A}} \mathrm{R}$, then blocking the $\mathrm{GABA}_{\mathrm{A}}$ Rs should prevent changes in mPSC amplitude triggered by manipulating $\mathrm{nAChR}$ function. To block $\mathrm{GABA}_{\mathrm{A}} \mathrm{R}$ activation completely, we injected the $\mathrm{GABA}_{\mathrm{A}} \mathrm{R}$ antagonist gabazine $(10 \mu \mathrm{M})$ at E8 and recorded mPSCs from spinal motoneurons at E10. As described previously, we found 
Table 1. mPSC characteristics

\begin{tabular}{|c|c|c|c|c|c|c|c|c|}
\hline Condition & Amplitude AMPA & Frequency AMPA & Decay AMPA & $n$ & Amplitude GABA & Frequency GABA & Decay GABA & $\bar{n}$ \\
\hline Control E8 -E10 & $8.1 \pm 0.4$ & $0.49 \pm 0.11$ & $4.3 \pm 0.9$ & 7 & $13.0 \pm 0.6$ & $0.56 \pm 0.32$ & $30.4 \pm 10.9$ & 7 \\
\hline Dhbe E8 -E10 & $10.4 \pm 0.6^{* *}$ & $0.59 \pm 0.15$ & $3.9 \pm 0.9$ & 8 & $16.6 \pm 1.3^{*}$ & $0.51 \pm 0.11$ & $25.5 \pm 10.2$ & 8 \\
\hline Gabazine E8 -E10 & $10.7 \pm 1.0^{* *}$ & $0.59 \pm 0.17$ & $4.1 \pm 0.5$ & 9 & $19.2 \pm 2.1^{* * *}$ & $0.49 \pm 0.11$ & $26.6 \pm 3.7$ & 9 \\
\hline Gabazine nicotine E8-E10 & $10.8 \pm 0.5^{* * *}$ & $0.33 \pm 0.11$ & $3.9 \pm 0.6$ & 14 & $18.6 \pm 0.7^{* * *}$ & $0.50 \pm 0.15$ & $25.8 \pm 11.5$ & 17 \\
\hline Lidocaine E8 -E10 & $12.6 \pm 1.3^{* * *}$ & $1.11 \pm 0.37$ & $4.4 \pm 1.1$ & 8 & $17.3 \pm 2.8^{*}$ & $0.47 \pm 0.18$ & $22.3 \pm 10.3$ & 8 \\
\hline Lidocaine nicotine E8 -E10 & $7.0 \pm 0.4$ & $0.58 \pm 0.12$ & $4.2 \pm 1.4$ & 9 & $9.0 \pm 0.3^{*}$ & $0.50 \pm 0.22$ & $23.5 \pm 6.6$ & 9 \\
\hline Nicotine E8 $12 \mathrm{~h}$ & $9.5 \pm 0.7^{* *}$ & $0.27 \pm 0.08$ & $4.8 \pm 0.2$ & 7 & $16.8 \pm 2.0$ & $0.43 \pm 0.08^{*}$ & $20.6 \pm 1.3$ & 7 \\
\hline Control acute E8 & $10.9 \pm 1.0$ & $0.28 \pm 0.04$ & $4.1 \pm 0.2$ & 10 & $15.4 \pm 0.9$ & $0.32 \pm 0.05$ & $20.8 \pm 1.8$ & 11 \\
\hline Nicotine acute E8 & $10.4 \pm 0.9$ & $0.44 \pm 0.11$ & $5.7 \pm 1.3$ & 7 & $17.9 \pm 1.1$ & $0.62 \pm 0.08^{* *}$ & $19.2 \pm 0.8$ & 7 \\
\hline DCG-IV acute E8 & $12.0 \pm 1.3$ & $0.46 \pm 0.16$ & $3.3 \pm 0.9^{*}$ & 9 & $16.1 \pm 1.7$ & $0.17 \pm 0.05^{*}$ & $26.1 \pm 1.1^{*}$ & 9 \\
\hline Control E8 -E10 & $9.0 \pm 1.0$ & $0.39 \pm 0.07$ & $4.1 \pm 0.2$ & 7 & $15.0 \pm 2.7$ & $0.40 \pm 0.11$ & $20.6 \pm 1.2$ & 7 \\
\hline
\end{tabular}

Amplitude, frequency, decay constant of AMPA, and GABA mPS(s are shown for different conditions. The numbers of cells for each condition are also shown, along with significant differences $\left({ }^{*} p<0.05 ; * * 0<0.01 ; * * * p<0.001\right)$. Values are clustered into four groups for statistical comparisons. The first group includes embryos treated with DH $\beta \mathrm{E}$, gabazine, DH $\beta \mathrm{E} /$ gabazine, nicotine/gabazine, lidocaine, lidocaine/nicotine, or control from E8 -E10 (GABA mPSC amplitude: ANOVA with post hoc Tukey test for multiple comparisons; GABA mPSC frequency and AMPA mPSC amplitude and frequency: Kruskal-Wallis nonparametric test with Conover-Iman procedure for multiple comparisons). The second group includes embryos treated with nicotine for $12 \mathrm{~h}$ or control (Student's $\mathrm{t}$ test was used for all parameters except AMPA mPSC decay: Kruskal-Wallis nonparametric test). The third group includes embryos acutely treated with nicotine, DCG-IV, or controls at E8 (AMPA mPSC amplitude, GABA mPSC decay: ANOVA with post hoc Tukey test for multiple comparisons; all other parameters: Kruskal-Wallis nonparametric test with Conover-Iman procedure for multiple comparisons). The fourth group includes embryos treated with nicotine, DCG-IV, or controls from E8-E10 (all Kruskal-Wallis nonparametric test with Conover-Iman procedure for multiple comparisons).

that gabazine triggered an increase in both AMPA and GABA mPSC amplitude (Fig. 6, Table 1). All of the distributions demonstrated a multiplicative scaling compared with controls (data not shown).

To test the idea that nicotinic modulator-mediated scaling is dependent on $\mathrm{GABA}_{\mathrm{A}} \mathrm{R}$ activation, we treated embryos with a combination of gabazine plus a nicotinic modulator. First, we treated embryos from E8 to E10 by injecting both gabazine and $\mathrm{DH} \beta \mathrm{E}$ in ovo at E8. This treatment led to an upward scaling of AMPA and GABA mPSC amplitude that was indistinguishable from that of gabazine treatment alone (Fig. 6, Table 1). This finding suggested that upscaling produced by inhibiting either $n A C h R s$ or $G_{A B A}$ Rs was not additive, consistent with the idea that both processes were acting through $\mathrm{GABA}_{\mathrm{A}}$ Rs. Next, we treated embryos from E8 to E10 by in ovo injections of a combination of gabazine and nicotine at E8. We found that, although nicotine alone caused a downscaling of mPSCs, nicotine and gabazine triggered an upscaling of AMPA and GABA mPSCs that was no different from gabazine treatment by itself (Fig. 6, Table 1). These results suggested that nicotinic modulators triggered bidirectional scaling through far more mild changes in $G_{A B A} R$ activation than complete $\mathrm{GABA}_{\mathrm{A}} \mathrm{R}$ blockade.

\section{Upscaling was converted to downscaling by increasing spontaneous GABA release alone}

We were surprised by the observation that simply reducing GABA vesicle release with $\mathrm{DH} \beta \mathrm{E}$ caused an upscaling that was equivalent to completely blocking $\mathrm{GABA}_{\mathrm{A}} \mathrm{R}$ activation (Figs. 2, 6, Table 1). Further, we could produce downscaling by slight increases in GABA release. This dramatic control of scaling by nicotinic modulators was even more surprising because, in our previous study, the predominant effect of nicotine and $\mathrm{DH} \beta \mathrm{E}$ was on AP-independent spontaneous release (Gonzalez-Islas et al., 2016). To test the idea that scaling could be triggered by alterations in $\mathrm{GABA}_{\mathrm{A}} \mathrm{R}$ activation due to spontaneous release, we blocked spike activity (SNA) by infusing a solution containing the voltage-gated $\mathrm{Na}^{+}$channel blocker lidocaine into the egg from E8 to E10 (Gonzalez-Islas and Wenner, 2006). This caused an upscaling of AMPA mPSC amplitude, as described previously (Fig. $7 A-D$, Table 1). We restored some of the $\mathrm{GABA}_{\mathrm{A}} \mathrm{R}$ activation that was lost due to action potential (AP) blockade (lidocaine) by also treating embryos with nicotine from E8 to E10 (lidocaine + nicotine) and increasing spontaneous GABA release. Strikingly, by simply increasing spontaneous GABA release with nicotine, we prevented the lidocaine-induced AMPAergic upscaling (Fig. $7 A-D$, Table 1). In fact, the distribution of AMPAergic mPSC amplitudes clearly shifted to the left of the control distribution, suggesting a downscaling (Fig. 7C). Similarly, lidocaine treatment led to GABAergic upscaling and lidocaine + nicotine converted this upscaling to downscaling (Fig. $7 E-H$, Table 1$)$. The results suggested that synaptic scaling could be highly regulated by AP-independent spontaneous release in the developing spinal network in vivo.

\section{Reducing spontaneous GABA release through an mGluR2 agonist triggered upscaling in vivo}

To confirm the observation that altering GABAergic spontaneous release by itself was capable of triggering scaling, we sought a separate method for altering GABAergic release. Previous work had suggested that mGluR2 agonists (e.g., DCG-IV) reduced spontaneous GABAergic release in different systems including the spinal cord (Poncer et al., 1995; Doi et al., 2002; Glitsch, 2006; Zhou et al., 2011). We therefore tested and found that acute DCG-IV application ( $5 \mu \mathrm{M})$ produced a decrease in GABA, but not AMPA, mPSC frequency in E8 motoneurons (Fig. $8 A, B$, Table 1). DCG-IV's effect on GABA mPSC frequency was observed throughout the $4-6 \mathrm{~h}$ recording period. Acute DCG-IV application had no effect on GABA or AMPA mPSC amplitude (Fig. $8 C$, Table 1), although it did alter the AMPA and GABA mPSC decay constant (Table 1). Next, we tested whether DCG-IV had effects on evoked GABAergic PSCs. We stimulated a slip of the VLF containing interneurons that project directly to motoneurons while recording the motoneuron population potential from the ventral root using suction electrode recordings. We isolated the GABAergic response by blocking glutamate receptors (CNQX and APV) and measuring the earliest, likely 
A
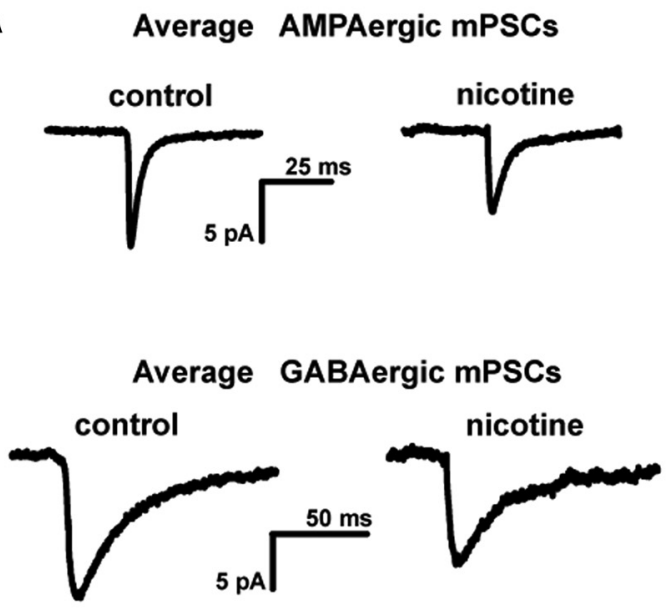

C

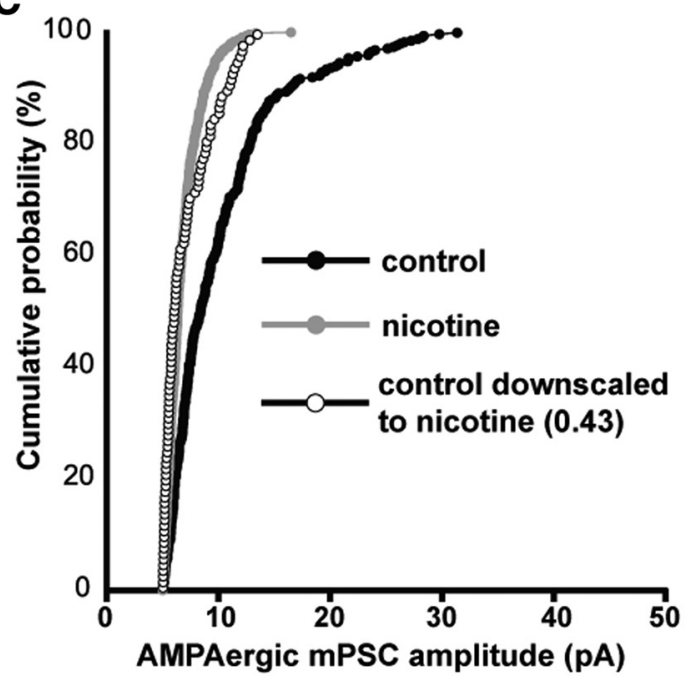

B

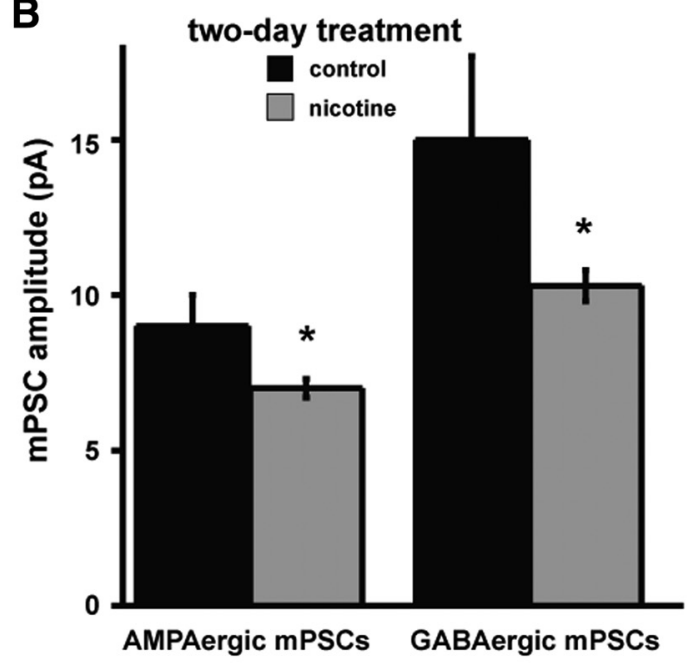

D

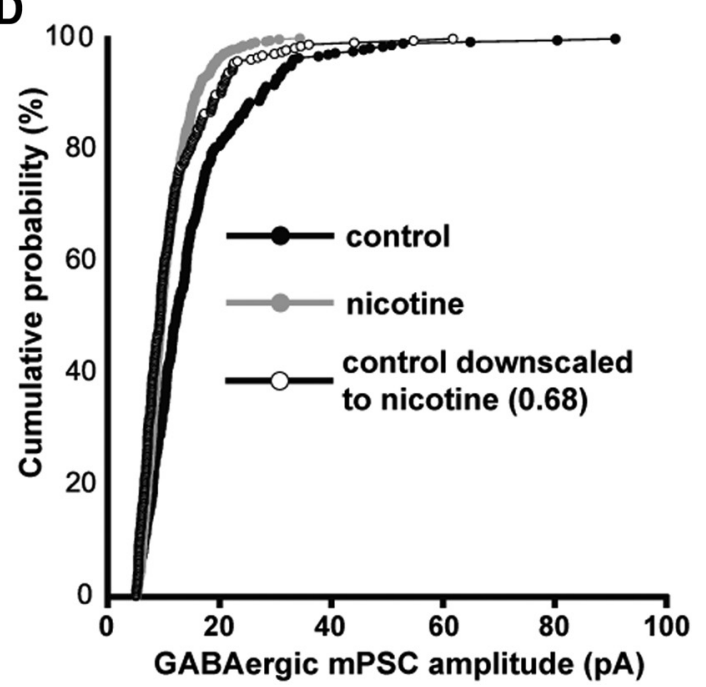

Figure 3. In ovo chronic nicotine treatment triggers AMPAergic and GABAergic synaptic downscaling. $A$, Representative single-cell averages of control AMPA or GABA mPSCs or after nicotine treatment (E8-E10). B, Bar chart showing average values of AMPAergic or GABAergic mPSC amplitude for control embryos or those chronically treated with nicotine (10 $\mu \mathrm{m}$ ). Error bars represent SE and significantly different values are indicated $\left({ }^{*} p<0.05\right)$. C, Cumulative probability plots for AMPAergic $\mathrm{mPSC}$ amplitudes (control embryos, $n=7 ;$ nicotine-treated embryos, $n=11$ ). Amplitudes were shifted to the left after nicotine treatment and demonstrated the scaling profile (as shown by plotting the scaled control distribution multiplied by 0.43 and removing values that fell below $5 \mathrm{pA}$ ). $\boldsymbol{D}$, Cumulative probability plots for GABAergic mPSC amplitudes (control embryos, $n=7$; nicotine-treated embryos, $n=11$ ). Amplitudes were shifted to the left after nicotine treatment and demonstrated the scaling profile (as shown by plotting the scaled control distribution multiplied by 0.68 and removing values that fell below 5 pA). Data for controls in $\boldsymbol{A}-\boldsymbol{D}$ are different from those used in Figure 2.

monosynaptic, part of the potential (Fig. 8D). The evoked GABAergic response was either unaffected or slightly reduced by DCG application ( $5 \mu \mathrm{M})$, but appeared to recover quickly. To determine whether DCG-IV affected SNA-driven movements, we monitored embryonic movements after E8 in ovo injection of DCG-IV $(2 \mu \mathrm{M})$. We found that embryonic movements were initially reduced, but fully recovered $2 \mathrm{~h}$ after drug injection (Fig. $8 E$ ). We reasoned that, if DCG-IV reduced spontaneous GABA release, and reduced $\mathrm{GABA}_{\mathrm{A}} \mathrm{R}$ activation due to spontaneous release was key to triggering upscaling, then $2 \mathrm{~d}$ of in ovo treatment with DCG-IV should trigger upscaling. Indeed, chronic DCG-IV $(2 \mu \mathrm{M})$ triggered increased AMPAergic and GABA ergic mPSC amplitude (Fig. 9, Table 1). Further, amplitude distributions demonstrated the characteristic scaling profile (Fig. 9E,F). Together, the results show that manipulation of $\mathrm{GABA}_{\mathrm{A}} \mathrm{R}$ activation by altering spontaneous GABA release using two different techniques triggers scaling in the living embryonic spinal cord.

\section{Discussion}

Bidirectional synaptic scaling triggered by altering spontaneous GABA release

SNA is a ubiquitous feature of nascent circuits and, in the developing spinal cord, is important in muscle/joint development (Ruano-Gil et al., 1978; Roufa and Martonosi, 1981) and axonal pathfinding (Hanson and Landmesser, 2004). We have determined that infusing a voltage-gated $\mathrm{Na}^{+}$channel blocker (lidocaine) into the living embryo for $2 \mathrm{~d}$ blocked SNAgenerated embryonic movements and produced a scaling up of both AMPA and GABA $\mathrm{APSC}$ amplitudes (Gonzalez-Islas and Wenner, 2006). Scaling is thought to be triggered by reductions in baseline spiking as a compensatory mechanism to reestablish spike rate. Although embryonic movements did not actually recover in the presence of lidocaine, we did observe a homeostatic recovery after blockade of either of the main excitatory neurotransmitter receptors. In ovo blockade 
A

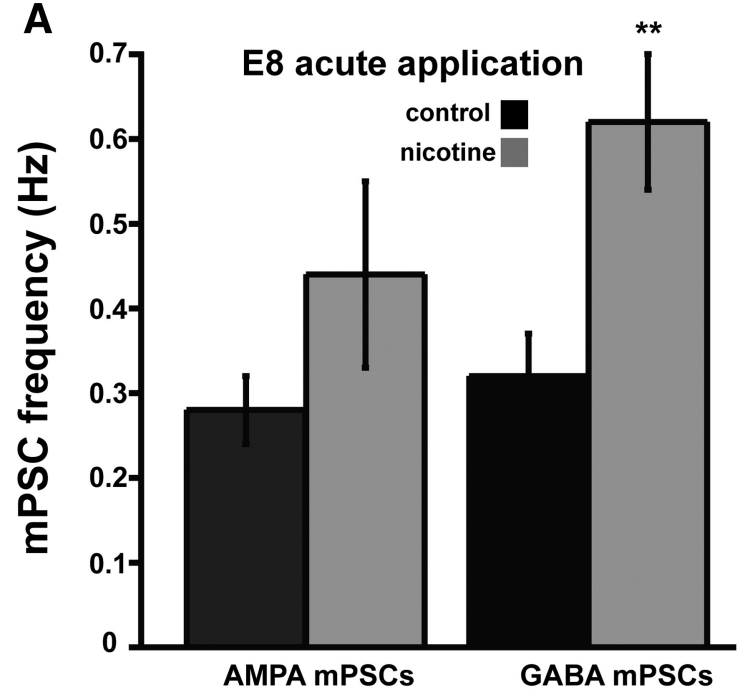

C

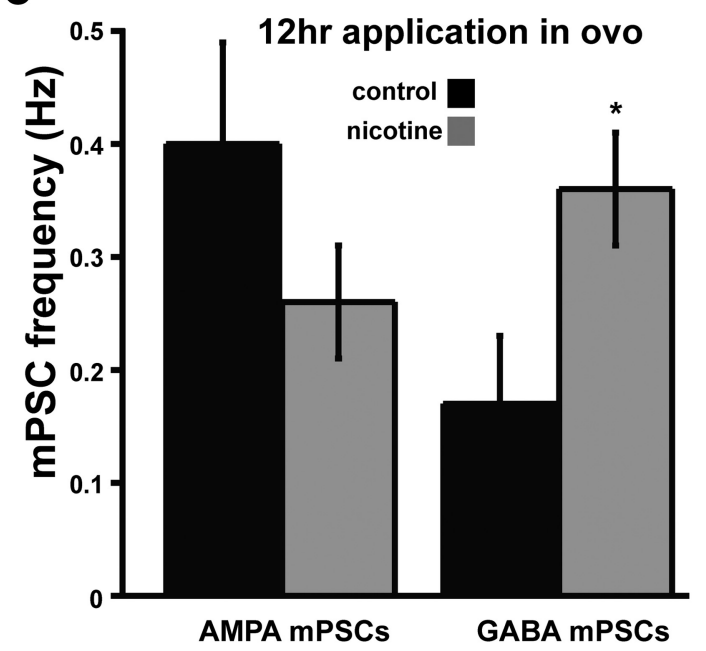

B

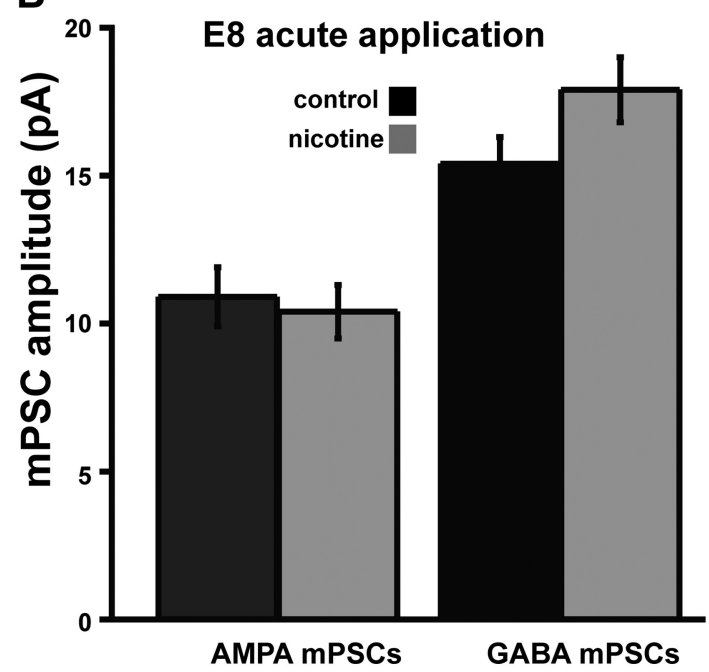

D

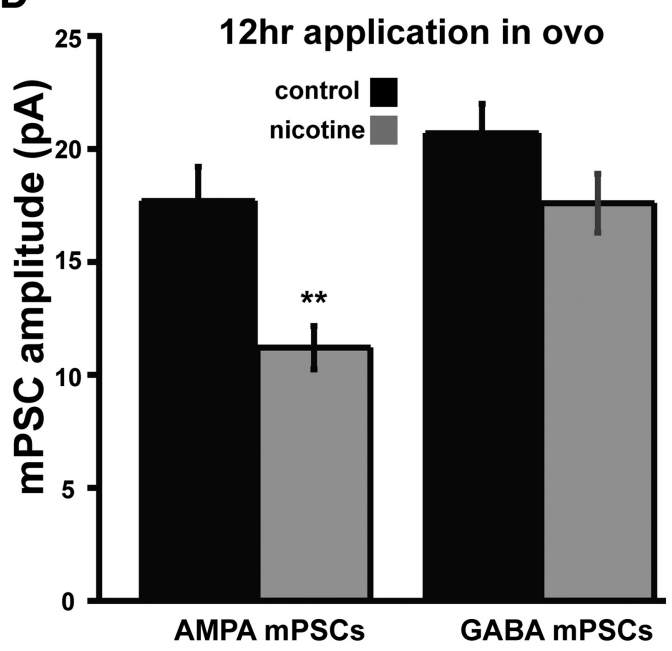

Figure 4. Nicotine increases GABAergic mPSC frequency at E8 and this is maintained for at least $12 \mathrm{~h}$. $\boldsymbol{A}, \boldsymbol{B}$, Bar charts showing that acute bath application of nicotine at E8 increases GABA, but not AMPA, mPSC frequency $(\boldsymbol{A})$ and has no effect on GABA or AMPA mPSC amplitude $(\boldsymbol{B})$ in spinal motoneurons. $\boldsymbol{C}, \boldsymbol{D}$, Bar charts showing that $12 \mathrm{~h}$ of in ovo nicotine treatment starting at E8 maintains an increase of GABA mPSC frequency $(\boldsymbol{C})$ and reduces AMPA mPSC amplitude $(\boldsymbol{D})$. Error bars represent SE and show a significant difference from controls $\left({ }^{*} p<\right.$ $\left.0.05,{ }^{* *} p<0.01\right)$.

of $\mathrm{GABA}_{\mathrm{A}} \mathrm{Rs}$ or glutamatergic receptors at E8 transiently reduced embryonic movements, which then recovered to normal levels $12 \mathrm{~h}$ after drug injection, even though antagonists remained effective throughout this period (Wilhelm and Wenner, 2008). Because both $\mathrm{GABA}_{\mathrm{A}} \mathrm{R}$ and glutamate receptor antagonists reduced embryonic movements similarly, we might have expected that either perturbation would trigger upscaling, but only $\mathrm{GABA}_{\mathrm{A}} \mathrm{R}$ blockade induced scaling. This result was consistent with the idea that reduced activation of $\mathrm{GABA}_{\mathrm{A}}$ Rs triggered scaling rather than SNA-dependent spiking.

In the current study, we provide even stronger support for the idea that scaling was triggered by alterations in $G_{A B A} R$ activation. We did this by modulating presynaptic GABA release and therefore $\mathrm{GABA}_{\mathrm{A}} \mathrm{R}$ activation through $\mathrm{nAChR}$ modulators (Gonzalez-Islas et al., 2016) or an mGluR2 agonist. Nicotine increased and Dh $\beta$ E or DCG-IV decreased baseline GABA vesicle release. Here, we show for the first time that increasing $\mathrm{GABA}_{\mathrm{A}}$ receptor activation chronically in ovo with nicotine triggered downscaling and, for GABAergic mPSCs, this was mediated by reductions in $\mathrm{CI}_{\mathrm{in}}^{-}$. Further, chronically decreasing GABA release triggered upscaling of AMPA and $\mathrm{GABA}_{\mathrm{A}}$ mPSC amplitudes. GABAergic upscaling was mediated by an increase in $\mathrm{CI}_{\text {in }}^{-}$, the same mechanism mediating scaling after GABAergic blockade (Lindsly et al., 2014). In addition, we showed that the ability of the nicotinic modulators to trigger bidirectional scaling was dependent on $\mathrm{GABA}_{\mathrm{A}}$ receptor activation (Fig. 6). The results show that scaling can be triggered in vivo through a physiologically relevant alteration of $\mathrm{GABA}_{\mathrm{A}} \mathrm{R}$ activation.

Because $G_{A B A} R$ activation is greatest during bouts of SNA, we had assumed that scaling was triggered by alterations in GABAergic signaling associated with bursts of SNA. However, in the interburst interval, there is also spike-dependent and spike-independent GABA release that activates $\mathrm{GABA}_{\mathrm{A}} \mathrm{Rs}$. Strikingly, our findings strongly argue that scaling was triggered by $\mathrm{GABA}_{\mathrm{A}} \mathrm{R}$ activation due to $\mathrm{AP}$-independent spontaneous GABA release. First, downscaling was triggered after 
A

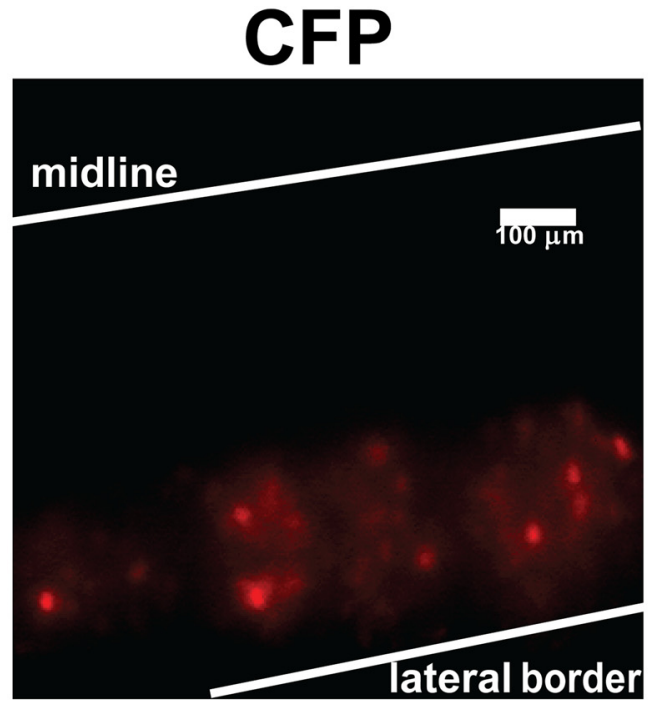

C

\section{regions of intrest (ROls)}

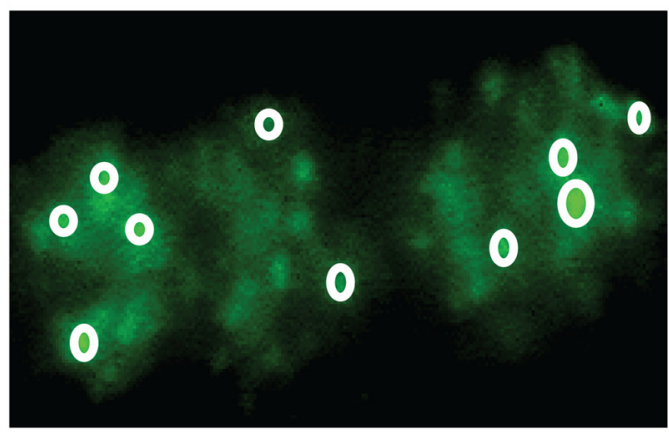

B

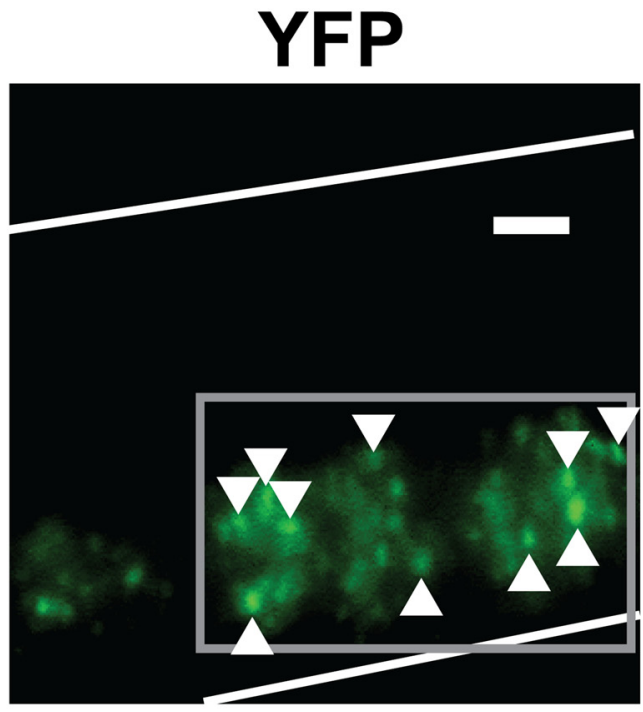

D

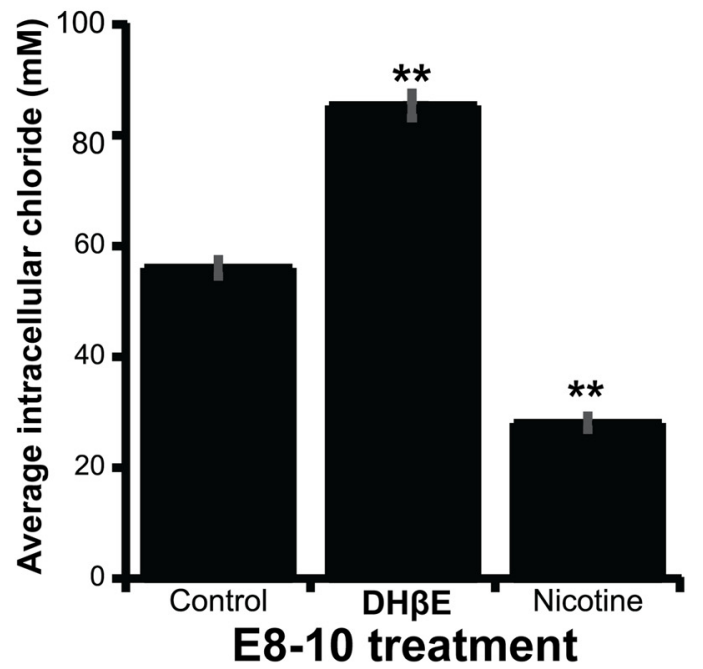

Figure 5. GABAergic scaling is mediated by changes in intracellular chloride. $\boldsymbol{A}-\boldsymbol{C}$, Images showing ventral view of Clomeleon-labeled neurons from an isolated E10 control spinal cord imaging with CFP illumination and using either CFP emission filter $(\boldsymbol{A})$ or YFP emission filter $(\boldsymbol{B})$ showing ROIs drawn around cells $(\boldsymbol{C})$ expanded from the box in $\boldsymbol{B}$. $\boldsymbol{D}$, Bar chart showing CI $\mathrm{I}_{\text {in }}^{-}$values converted from ratios from five different cords in each condition (10 cells/cord used to establish cord value). Error bars represent $\operatorname{SE}\left({ }^{* *} p<0.01\right)$.

chronically increasing spontaneous GABA release with nicotine (Figs. 3, 4). Second, nicotine was also capable of converting upscaling produced by chronic lidocaine-treatment to downscaling (lidocaine + nicotine) through a spikeindependent mechanism (Fig. 7). Third, scaling triggered by nicotinic modulators was dependent on $\mathrm{GABA}_{\mathrm{A}} \mathrm{R}$ activation (Fig. 6). Fourth, we were able to trigger upscaling with DCG-IV, which reduced spontaneous GABA release but had only minimal effects on embryonic movements or evoked GABA release (Figs. 8, 9). Together, our findings provide a strong argument that alterations in spontaneous release trigger scaling and extend similar findings in vitro to an in vivo system (see below). This result suggests that a function of spontaneous release is for the homeostatic regulation of synaptic strength.

\section{SNA does not appear to be controlled homeostatically} by scaling

Although our initial studies suggested the possibility that scaling was triggered as a means to homeostatically maintain SNA, we now think that this is unlikely. First, the actual homeostatic recovery of embryonic movements after $\mathrm{GABA}_{\mathrm{A}} \mathrm{R}$ blockade occurs several hours before the expression of upscaling (Wilhelm and Wenner, 2008; Lindsly et al., 2014). Second, there are multiple examples in which upscaling or downscaling was expressed in embryonic motoneurons, but SNA frequency in the spinal preparation was unchanged (Fig. $1 B$; Lindsly et al., 2014). Similar results have been described in the embryonic zebrafish spinal cord (Knogler et al., 2010). Finally, an identical nicotine-induced downscaling was observed whether SNA-driven movements were increased (nicotine) or virtually eliminated (nicotine/lidocaine). This finding suggested that spontaneous GABAergic neurotransmission was more important in triggering scaling than GABAergic transmission driven by bursts of spiking during SNA. Therefore, the signaling cascades that mediate scaling must be sensitive to smaller GABAergic quantal currents associated with spontaneous release or single APs rather than to the strong GABAergic depo- 
A

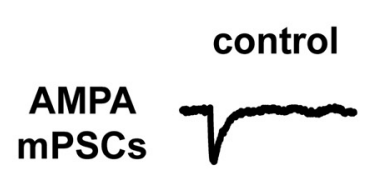

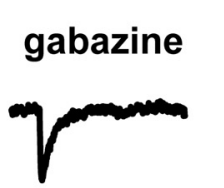
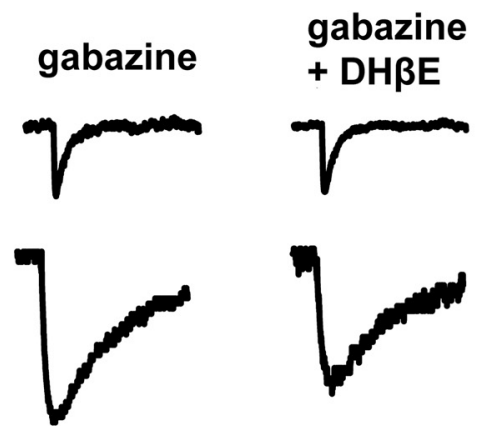

gabazine
+nicotine

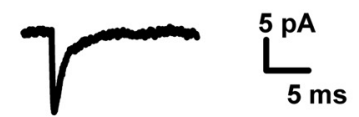

B

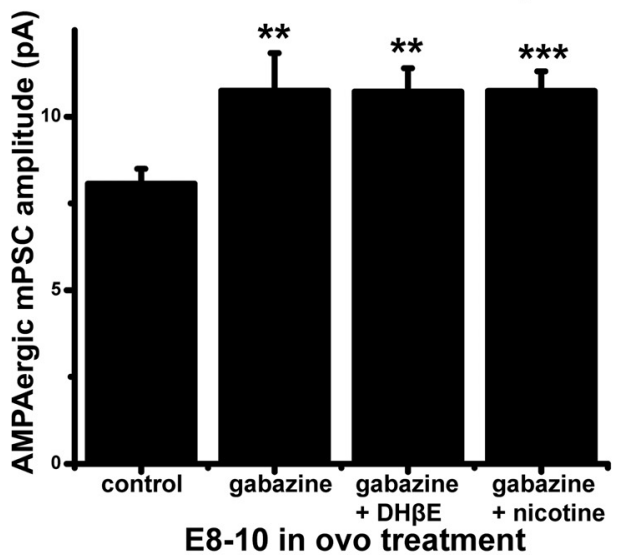

D

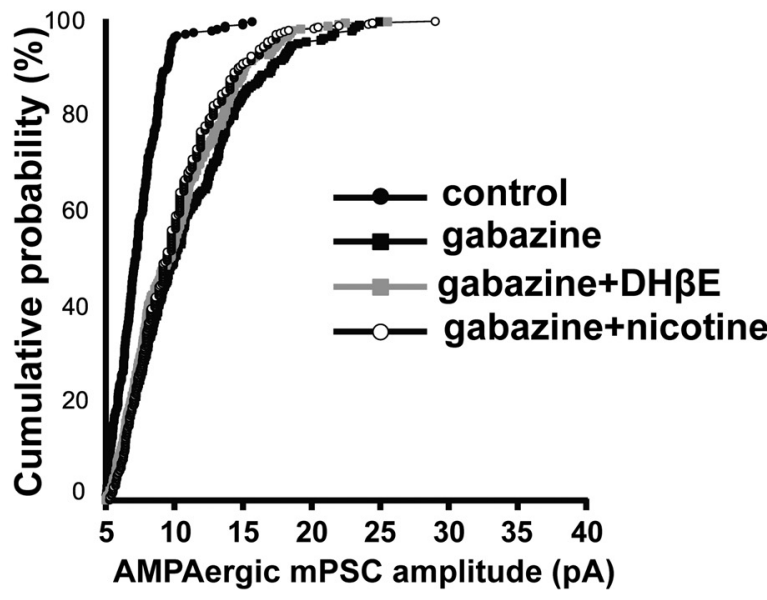

C
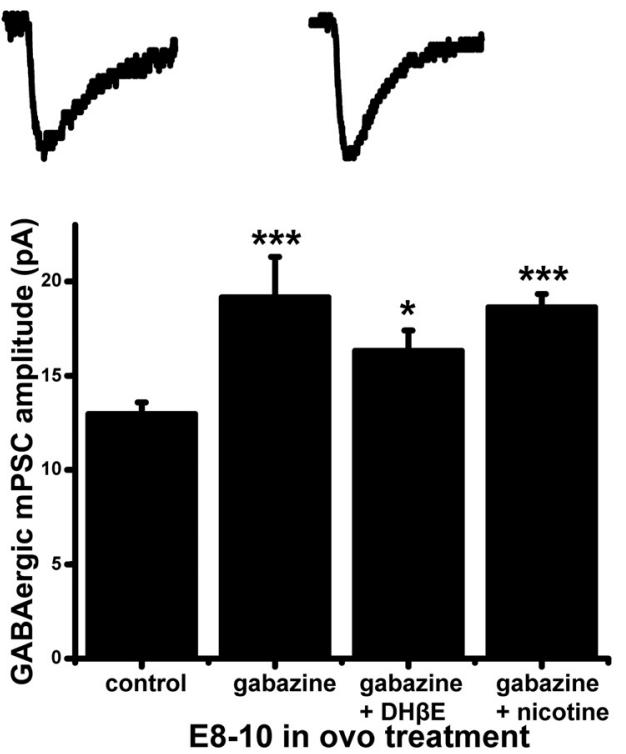

E

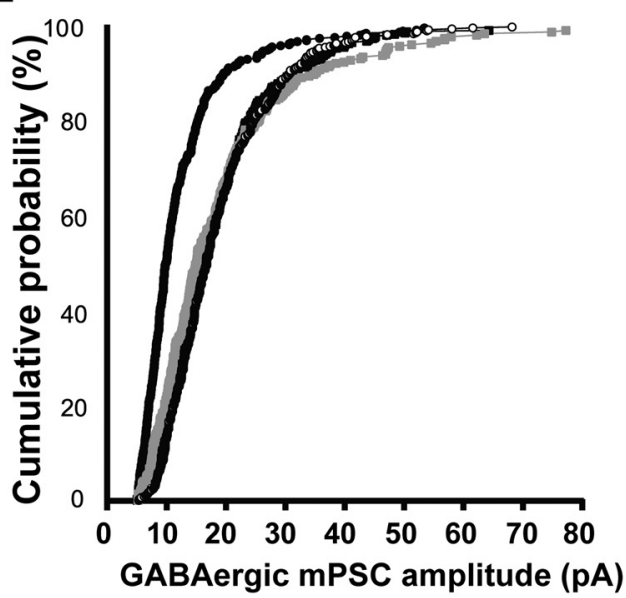

Figure 6. Synaptic scaling induced by nicotine receptor modulation is dependent on $G A B A_{A} R$ activation. $A$, Representative single-cell average of AMPA and GABA mPSCs after different chronic treatments. $\boldsymbol{B}, \boldsymbol{C}$, Bar chart showing average values of AMPAergic $(\boldsymbol{B})$ and GABAergic $(\boldsymbol{C}) \mathrm{mEPSC}$ amplitude for motoneurons from control embryos and embryos treated with gabazine (10 $\mu \mathrm{M}$ ), gabazine $+\operatorname{DH} \beta E(5 \mu \mathrm{m})$, or gabazine + nicotine $(10 \mu \mathrm{m})$. Error bars represent SE and show a significant difference from controls $\left({ }^{*} p<0.05,{ }^{* *} p<0.01,{ }^{* * *} p<0.001\right)$. D, Cumulative probability plot for AMPAergic mEPSC amplitudes (control embryos, $n=7$; gabazine-treated embryos, $n=7$; gabazine/DH $\beta$ E-treated embryos, $n=10$; gabazine/nicotine-treated embryos, $n=7$ ). $E$, Cumulative probability plot for GABAergic mEPSC amplitudes (control embryos, $n=7$; gabazine-treated embryos, $n=8$; gabazine/DH $\beta$ E-treated embryos, $n=9$; gabazine/nicotinetreated embryos, $n=7$ ). Controls are the same as in Figure 2.

larizations that lead to bursts of spiking and produce large calcium transients during SNA.

Triggering synaptic scaling

Understanding the triggers for synaptic scaling is important for elucidating the function of this form of plasticity. Although it is clear that altering $\mathrm{GABA}_{\mathrm{A}} \mathrm{R}$ activation triggers scaling in the embryonic spinal cord, this is the first demonstration that changes in AP-independent release trigger scaling in vivo. However, reductions in glutamate receptor activation due to spontaneous release have been shown to trigger AMPAergic upward scaling in cultured networks (Sut- ton et al., 2006; Aoto et al., 2008; Wang et al., 2011; Fong et al., 2015; Kavalali, 2015). It has been shown recently that upscaling can be triggered by reduced mEPSC-dependent receptor activation, which can lead to calcium entry that is amplified through calcium-induced calcium release (Reese and Kavalali, 2015). Such signaling may be triggered through $G_{A B A} R s$ early in development, when GABA is depolarizing; glutamatergic signaling may assume this role later in development, when GABA becomes hyperpolarizing. Blockade of spontaneous neurotransmission has also been shown to signal compensatory changes in motoneuron excitability and quantal content (Frank et al., 2006; Bichler et al., 2007). 


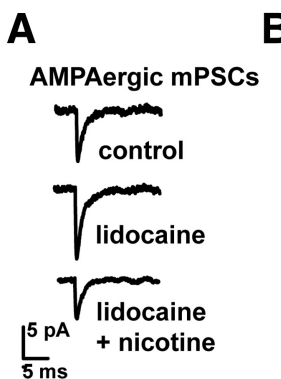

E

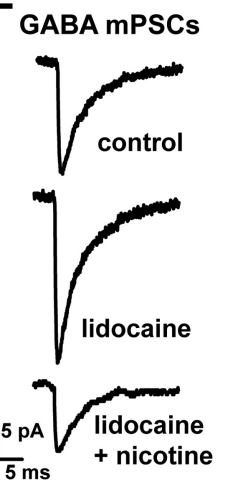

\section{B}

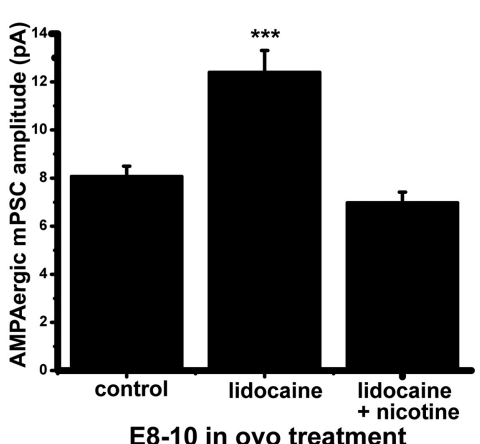

$\mathbf{F}$

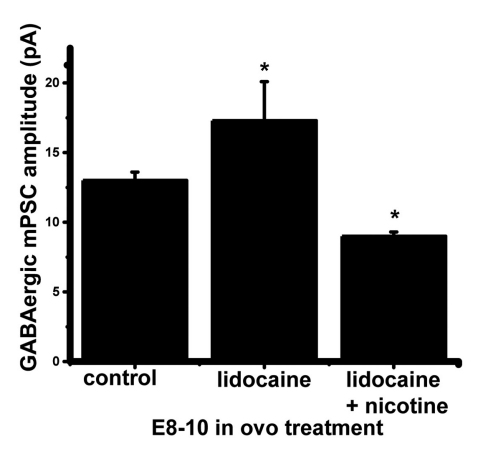

C

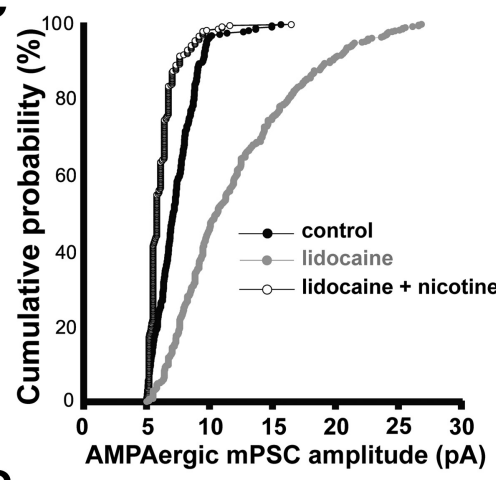

G

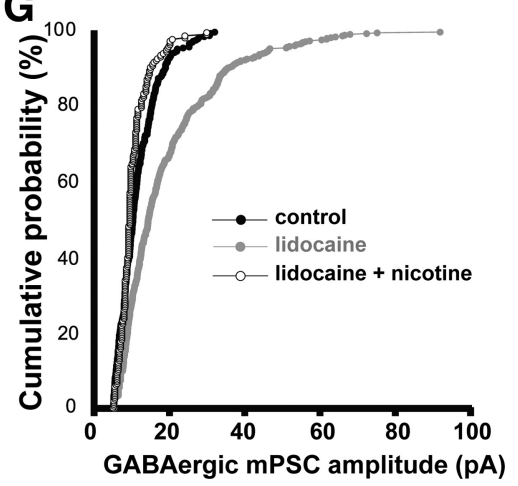

D

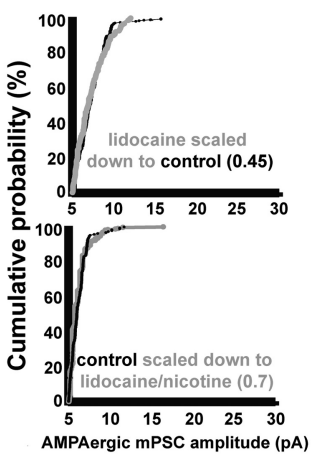

H

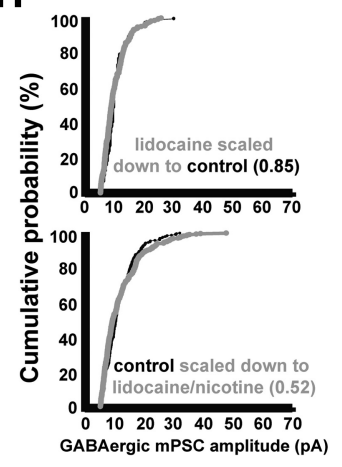

Figure 7. Upscaling is converted to downscaling by increasing spontaneous GABA release. $\boldsymbol{A}$, Representative single-cell average of AMPA mPS(s after different chronic treatments. $\boldsymbol{B}$, Bar chart showing average values of AMPAergic mEPSC amplitude for motoneurons from embryos receiving different treatments. Error bars represent $S E(* * * p<0.001)$. $C$, Cumulative probability plot for AMPAergic mPSC amplitudes (control embryos, $n=7$; lidocaine-treated embryos, $n=7$; lidocaine/nicotine-treated embryos, $n=8$ ). $\boldsymbol{D}$, Multiplicative relationship of AMPAergic mPSC amplitudes after activity blockade with or without nicotine. Larger mPSC amplitude distribution was multiplied by a scaling factor (in parentheses) that gave the best overlap with smaller distribution after removing values that fell below 5 pA; Kolmogorov-Smirnov test was then used to compare distributions. AMPAergic mPSCs from control and lidocaine-treated embryos (above) or lidocaine + nicotine-treated embryos (below) demonstrated a multiplicative relationship. $\boldsymbol{E}$, Representative single-cell average of GABA mPSCs after different chronic treatments. $F$, Bar chart showing average values of GABAergic mEPSC amplitude for motoneurons from embryos receiving different treatments. Error bars represent SE ( $\left.{ }^{*} p<0.05\right)$. G, Cumulative probability plot for GABAergic mPSC amplitudes (control embryos, $n=7$; lidocaine-treated embryos, $n=7$; lidocaine/nicotine-treated embryos, $n=8$ ). $\boldsymbol{H}$, Multiplicative relationship of GABAergic mPSC amplitudes after activity blockade with or without nicotine. Larger mPSC amplitude distribution was multiplied by a scaling factor (in parentheses) that gave the best overlap with smaller distribution after removing values that fell below $5 \mathrm{pA}$; Kolmogorov-Smirnov test was then used to compare distributions. AMPAergic mPSCs from control and lidocaine-treated embryos (above) or lidocaine + nicotine-treated embryos (below) demonstrated a multiplicative relationship. Controls are the same as in Figure 2.

In embryonic motoneurons, $\mathrm{GABA}_{\mathrm{A}} \mathrm{R}$ activation due to spontaneous release or spike-induced release of a single vesicle is likely to produce a similar response postsynaptically and activate similar signaling cascades. Therefore, it is possible that scaling could be triggered by altering the frequency of individual spikes in the interval between bursts of SNA. Consistent with this idea, $2 \mathrm{~d}$ of blockade of spiking with lidocaine treatment did trigger upscaling in embryonic motoneurons (Gonzalez-Islas and Wenner, 2006); however, lidocaine may reduce spontaneous release by reducing AP-dependent acetylcholine release. Although altering spontaneous release rate can trigger scaling, it is also clear that reducing spike rate in specific presynaptic inputs to a neuron in vitro and in vivo can trigger compensatory synaptic strengthening selectively at those inhibited inputs (Webb and Cope, 1992; Hou et al., 2008; Béique et al., 2011; Deeg and Aizenman, 2011). These synapse specific compensations appear to be due to changes in postsynaptic receptor activation rather than postsynaptic spiking, which remains unperturbed in most of these studies. Therefore, local synaptic compensations due to altered presynaptic spiking and cell-wide synaptic scaling triggered by changing spontaneous release at all synaptic inputs may represent similar plasticity mechanisms that only differ by the proportion of synaptic inputs perturbed. Consistent with this idea, blocking glutamate receptor activation at all of a cultured neuron's inputs triggers upward scaling (Sutton et al., 2006; Chen et al., 2014; Fong et al., 2015; Reese and Kavalali, 2015). Our findings are consistent with a neurotransmission-mediated plasticity that functions to maintain synaptic strength homeostatically.

Alternatively, reductions in postsynaptic spike rate also appear to trigger a form of upscaling that may be mechanistically distinct from neurotransmission-mediated synaptic compensations. Previous studies have suggested that altering spike rate can trigger scaling independently of effects on neurotransmission (Ibata et al., 2008; Goold and Nicoll, 2010). Further, neurotransmission-mediated scaling appears to be dependent on retinoic acid synthesis and FMRP, whereas spike-dependent scaling is not (Soden and Chen, 2010; Wang et al., 2011). However, these two plasticities may not be completely independent of one another because scaling triggered by altering neurotransmission is not sensitive to additional changes in spiking activity. For example, downscaling triggered by increasing GABAergic transmission was no different whether spiking was increased or abolished (Figs. 3, 7). Further, in cultured cortical neurons, we demonstrated that 
A

control

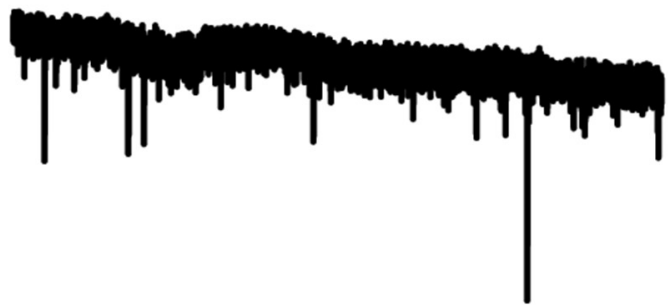

B
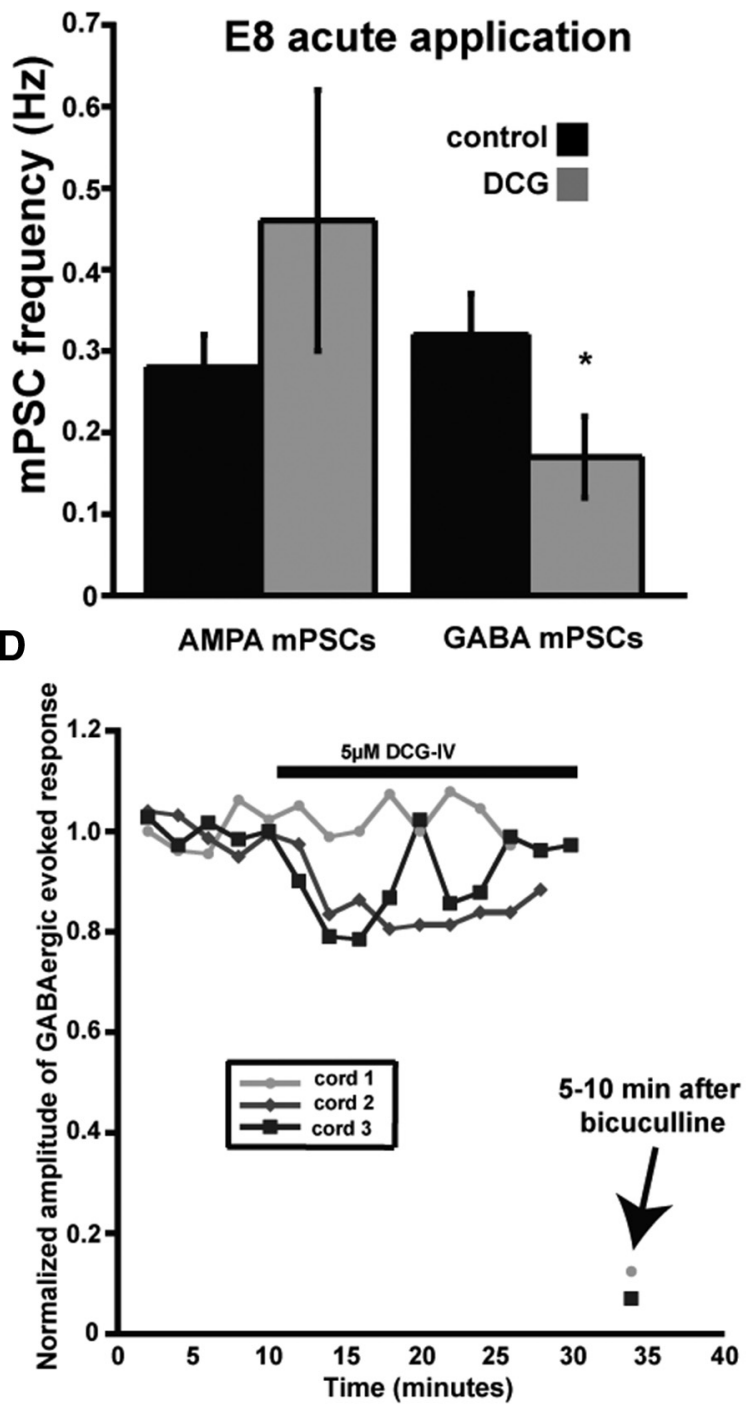

30 min after DCG-IV

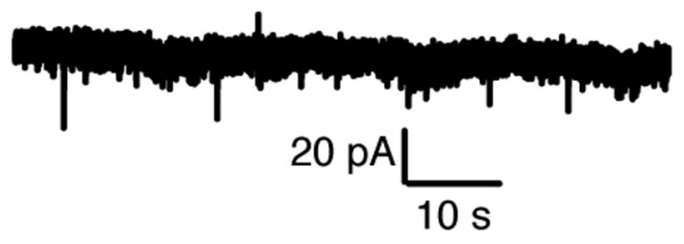

C

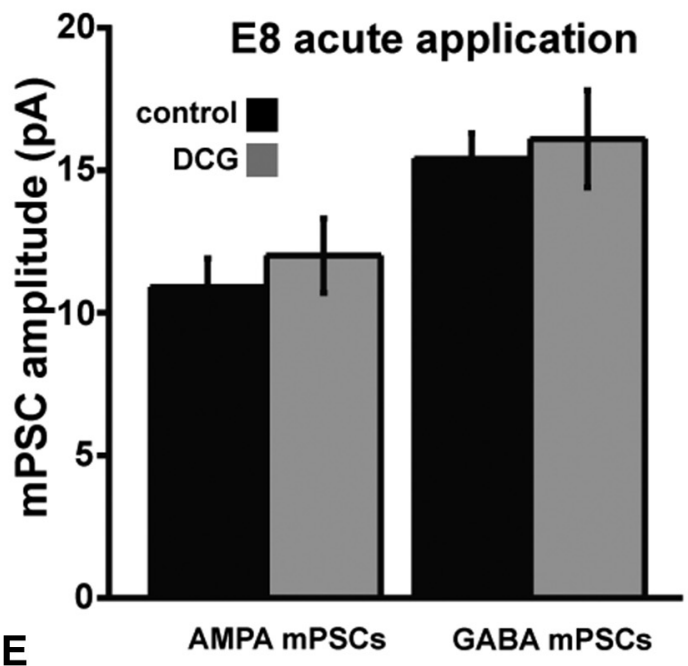

E

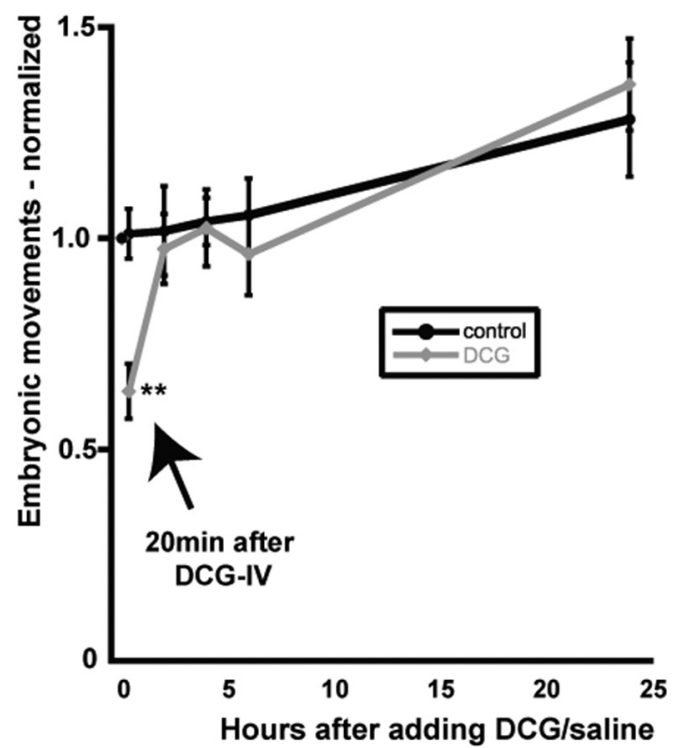

Figure 8. DCG-IV reduced GABA mPSC frequency, but only transiently influenced evoked GABAergic responses or in ovo embryonic movements. $A$, AMPA and GABA mPSCs observed in a single motoneuron before (control) and 30 min after adding DCG-IV $(5 \mu \mathrm{m})$ to the bath. $B$, Acute application of DCG-IV $(5 \mu \mathrm{m})$ decreased GABA, but not AMPA, mPSC frequency in the E8 spinal preparation. Error bars represent SE and show a significant difference from controls $\left({ }^{*} p<0.05\right)$. C, Acute application of DCG-IV had no effect on GABA or AMPA mPSC amplitude in the E8 spinal preparation. D, Acute application of DCG-IV $(5 \mu \mathrm{M})$ had no influence or transiently reduced VLF-evoked GABAergic potentials observed in ventral root recordings. $\boldsymbol{E}$, In ovo injection of DCG-IV $(2 \mu \mathrm{M})$ at E8 transiently reduced embryonic movements, which were then recovered $2 \mathrm{~h}$ after DCG-IV injection. Error bars represent SE and show a significant difference from controls $(* * 00.01)$.

scaling produced after $24 \mathrm{~h}$ of AMPAR blockade was no different whether spiking was reduced or normal (Fong et al., 2015).

It is also possible that reduced neurotransmitter activation is downstream of reductions in spike rate. This could explain why altering spiking has no effect when neurotransmission is perturbed. Reducing the frequency of isolated spikes could trigger upscaling by reducing AP-dependent transmitter release and thus receptor activation. Alternatively, recent work suggests a second possibility in which chronic spike blockade 
A

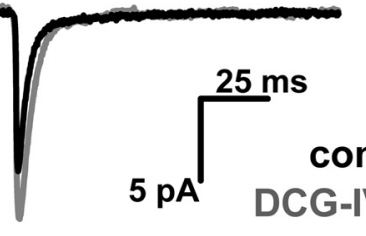

C

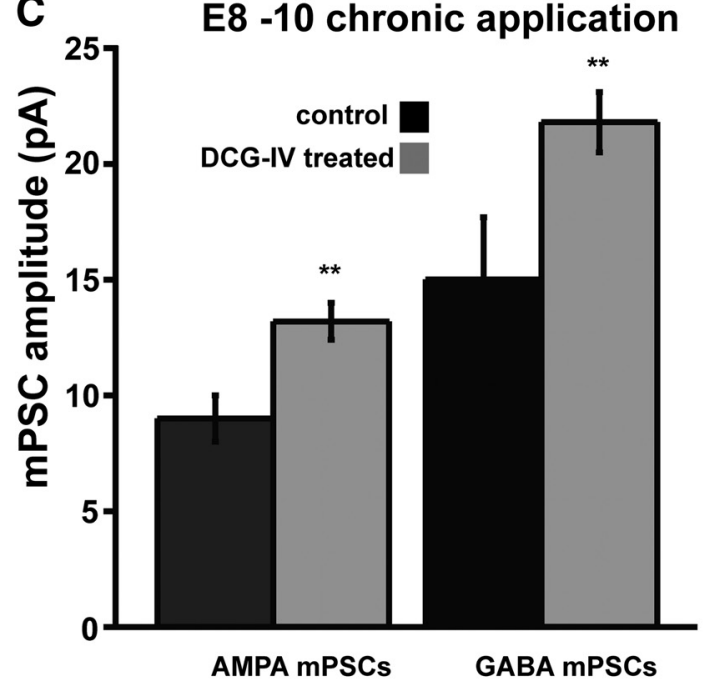

E

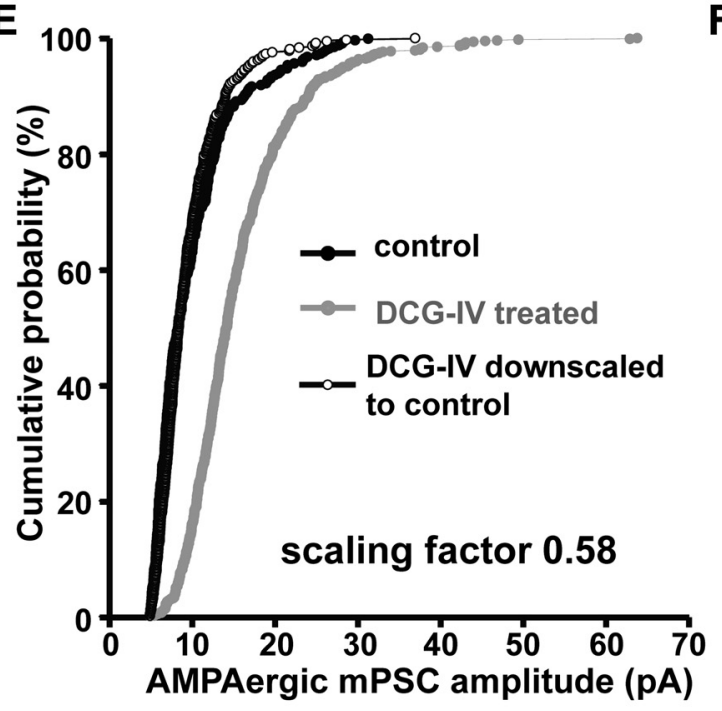

B

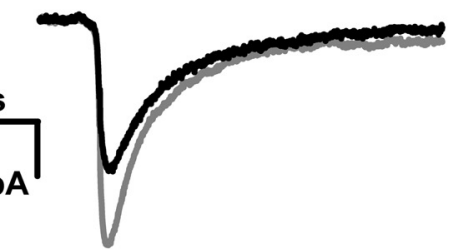

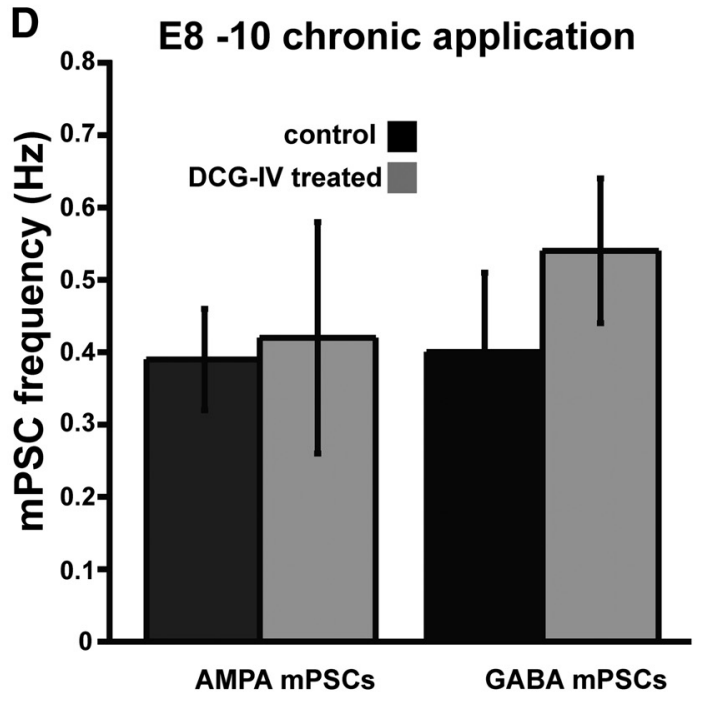

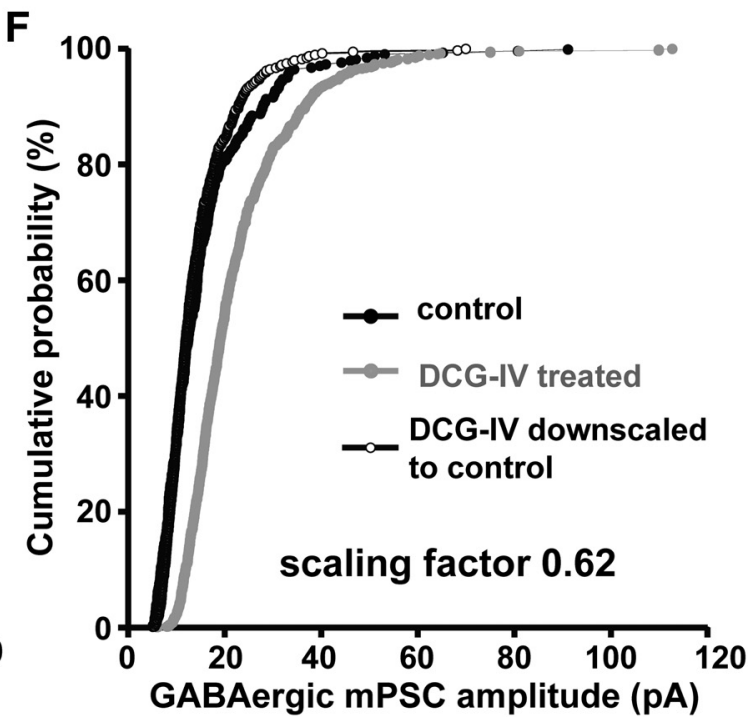

Figure 9. E8-E10 DCG-IV treatment in ovo triggers AMPAergic and GABAergic upscaling. $\boldsymbol{A}, \boldsymbol{B}$, Traces showing representative single-cell average of AMPA $(\boldsymbol{A})$ or GABA $(\boldsymbol{B}) \mathrm{mPSC}$ in control or DCG-IV $(2 \mu \mathrm{M})$ treated motoneurons. $\boldsymbol{C}, \boldsymbol{D}$, Bar charts showing average values of AMPAergic and GABAergic mPSC amplitude (C) or frequency (D) for motoneurons from embryos receiving different treatments. Error bars represent SE and show a significant difference from controls $\left(^{* *} p<0.01\right)$. E, Cumulative probability plot for AMPAergic mPSC amplitudes (control embryos, $n=7$; DCG-IV-treated embryos, $n=16$ ). Amplitudes were shifted to the right after DCG-IV treatment and demonstrated the scaling profile (as shown by plotting the scaled DCG-IV distribution multiplied by 0.58 and removing values that fell below $5 \mathrm{pA}$ ). $\boldsymbol{F}$, Cumulative probability plot for GABAergic mPSC amplitudes (control embryos, $n=7$; DCG-IV-treated embryos, $n=16$ ). Amplitudes were shifted to the right after DCG-IV treatment and demonstrated the scaling profile (as shown by plotting the scaled DCG-IV distribution multiplied by 0.62 and removing values that fell below $5 \mathrm{pA}$ ). Control data are the same as those shown in Figure 3.

triggers changes in DNA methylation status; these epigenetic changes have been shown to alter the frequency of spontaneous release and thereby could trigger scaling (Nelson et al., 2008; Qiu et al., 2012; Meadows et al., 2015; Yu et al., 2015; Sweatt, 2016). In this way, spike-dependent scaling is achieved through the recruitment of transmission-mediated plasticity.
Importance of nicotinic regulation of $\mathrm{GABA}_{\mathrm{A}} \mathrm{Rs}$ in embryonic development

Perturbing baseline tonic $n A C h R$ activation alters $G_{A B A} R$ activation and triggers synaptic scaling. SNA and nicotinic regulation of neurotransmitter receptor activation are widespread throughout the developing nervous system (Hellström-Lindahl et al., 1998; O’Donovan, 1999; Blanken- 
ship and Feller, 2010). Therefore, nicotinic regulation of GABA release could have profound implications for fetal exposure to drugs influencing $\mathrm{GABA}_{\mathrm{A}} \mathrm{R}$ activation, such as benzodiazepines or nicotine.

\section{References}

Aoto J, Nam CI, Poon MM, Ting P, Chen L (2008) Synaptic signaling by all-trans retinoic acid in homeostatic synaptic plasticity. Neuron 60: 308-320. CrossRef Medline

Béíque JC, Na Y, Kuhl D, Worley PF, Huganir RL (2011) Arc-dependent synapse-specific homeostatic plasticity. Proc Natl Acad Sci U S A 108: 816-821. CrossRef Medline

Ben-Ari Y (2001) Developing networks play a similar melody. Trends Neurosci 24:353-360. CrossRef Medline

Berglund K, Schleich W, Krieger P, Loo LS, Wang D, Cant NB, Feng G, Augustine GJ, Kuner T (2006) Imaging synaptic inhibition in transgenic mice expressing the chloride indicator, Clomeleon. Brain Cell Biol 35: 207-228. CrossRef Medline

Bichler EK, Carrasco DI, Rich MM, Cope TC, Pinter MJ (2007) Rat motoneuron properties recover following reinnervation in the absence of muscle activity and evoked acetylcholine release. J Physiol 585:47-56. CrossRef Medline

Blankenship AG, Feller MB (2010) Mechanisms underlying spontaneous patterned activity in developing neural circuits. Nat Rev Neurosci 11: 18-29. CrossRef Medline

Chen L, Lau AG, Sarti F (2014) Synaptic retinoic acid signaling and homeostatic synaptic plasticity. Neuropharmacology 78:3-12. CrossRef Medline

Davis GW (2013) Homeostatic signaling and the stabilization of neural function. Neuron 80:718-728. CrossRef Medline

Deeg KE, Aizenman CD (2011) Sensory modality-specific homeostatic plasticity in the developing optic tectum. Nat Neurosci 14:548-550. CrossRef Medline

Desai NS (2003) Homeostatic plasticity in the CNS: synaptic and intrinsic forms. J Physiol Paris 97:391-402. CrossRef Medline

Desai NS, Cudmore RH, Nelson SB, Turrigiano GG (2002) Critical periods for experience-dependent synaptic scaling in visual cortex. Nat Neurosci 5:783-789. Medline

Doi A, Ishibashi H, Jinno S, Kosaka T, Akaike N (2002) Presynaptic inhibition of GABAergic miniature currents by metabotropic glutamate receptor in the rat CNS. Neuroscience 109:299-311. CrossRef Medline

Dzhala V, Valeeva G, Glykys J, Khazipov R, Staley K (2012) Traumatic alterations in GABA signaling disrupt hippocampal network activity in the developing brain. J Neurosci 32:4017-4031. CrossRef Medline

Fong MF, Newman JP, Potter SM, Wenner P (2015) Upward synaptic scaling is dependent on neurotransmission rather than spiking. Nat Commun 6:6339. CrossRef Medline

Frank CA, Kennedy MJ, Goold CP, Marek KW, Davis GW (2006) Mechanisms underlying the rapid induction and sustained expression of synaptic homeostasis. Neuron 52:663-677. CrossRef Medline

Garcia-Bereguiain MA, Gonzalez-Islas C, Lindsly C, Butler E, Hill AW, Wenner P (2013) In vivo synaptic scaling is mediated by GluA2-lacking AMPA receptors in the embryonic spinal cord. J Neurosci 33:6791-6799. CrossRef Medline

Glitsch M (2006) Selective inhibition of spontaneous but not Ca2+dependent release machinery by presynaptic group II mGluRs in rat cerebellar slices. J Neurophysiol 96:86-96. CrossRef Medline

Goel A, Jiang B, Xu LW, Song L, Kirkwood A, Lee HK (2006) Cross-modal regulation of synaptic AMPA receptors in primary sensory cortices by visual experience. Nat Neurosci 9:1001-1003. CrossRef Medline

Gonzalez-Islas C, Wenner P (2006) Spontaneous network activity in the embryonic spinal cord regulates AMPAergic and GABAergic synaptic strength. Neuron 49:563-575. CrossRef Medline

Gonzalez-Islas C, Chub N, Garcia-Bereguiain MA, Wenner P (2010) GABAergic synaptic scaling in embryonic motoneurons is mediated by a shift in the chloride reversal potential. J Neurosci 30:13016-13020. CrossRef Medline

Gonzalez-Islas C, Garcia-Bereguiain MA, O'Flaherty B, Wenner P (2016) Tonic nicotinic transmission enhances spinal GABAergic presynaptic release and the frequency of spontaneous network activity. Dev Neurobiol 76:298-312. CrossRef Medline

Goold CP, Nicoll RA (2010) Single-cell optogenetic excitation drives homeostatic synaptic depression. Neuron 68:512-528. CrossRef Medline
Hamburger V, Hamilton HL (1951) A series of normal stages in the development of the normal chick embryo. J Morphol 88:49-92. CrossRef Medline

Hanson MG, Landmesser LT (2004) Normal patterns of spontaneous activity are required for correct motor axon guidance and the expression of specific guidance molecules. Neuron 43:687-701. CrossRef Medline

Hellström-Lindahl E, Gorbounova O, Seiger A, Mousavi M, Nordberg A (1998) Regional distribution of nicotinic receptors during prenatal development of human brain and spinal cord. Brain Res Dev Brain Res 108:147-160. CrossRef Medline

Hou Q, Zhang D, Jarzylo L, Huganir RL, Man HY (2008) Homeostatic regulation of AMPA receptor expression at single hippocampal synapses. Proc Natl Acad Sci U S A 105:775-780. CrossRef Medline

Ibata K, Sun Q, Turrigiano GG (2008) Rapid synaptic scaling induced by changes in postsynaptic firing. Neuron 57:819-826. CrossRef Medline

Kavalali ET (2015) The mechanisms and functions of spontaneous neurotransmitter release. Nat Rev Neurosci 16:5-16. CrossRef Medline

Knogler LD, Liao M, Drapeau P (2010) Synaptic scaling and the development of a motor network. J Neurosci 30:8871-8881. CrossRef Medline

Kuner T, Augustine GJ (2000) A genetically encoded ratiometric indicator for chloride: capturing chloride transients in cultured hippocampal neurons. Neuron 27:447-459. CrossRef Medline

Lee KF, Soares C, Béique JC (2014) Tuning into diversity of homeostatic synaptic plasticity. Neuropharmacology 78:31-37. CrossRef Medline

Lindsly C, Gonzalez-Islas C, Wenner P (2014) Activity blockade and GABAA receptor blockade produce synaptic scaling through chloride accumulation in embryonic spinal motoneurons and interneurons. PLoS One 9:e94559. CrossRef Medline

Marder E, Goaillard JM (2006) Variability, compensation and homeostasis in neuron and network function. Nat Rev Neurosci 7:563-574. CrossRef Medline

Meadows JP, Guzman-Karlsson MC, Phillips S, Holleman C, Posey JL, Day JJ, Hablitz JJ, Sweatt JD (2015) DNA methylation regulates neuronal glutamatergic synaptic scaling. Sci Signal 8:ra61. CrossRef Medline

Nelson ED, Kavalali ET, Monteggia LM (2008) Activity-dependent suppression of miniature neurotransmission through the regulation of DNA methylation. J Neurosci 28:395-406. CrossRef Medline

O’Brien RJ, Kamboj S, Ehlers MD, Rosen KR, Fischbach GD, Huganir RL (1998) Activity-dependent modulation of synaptic AMPA receptor accumulation. Neuron 21:1067-1078. CrossRef Medline

O'Donovan MJ (1999) The origin of spontaneous activity in developing networks of the vertebrate nervous system. Curr Opin Neurobiol 9: 94-104. CrossRef Medline

Poncer JC, Shinozaki H, Miles R (1995) Dual modulation of synaptic inhibition by distinct metabotropic glutamate receptors in the rat hippocampus. J Physiol 485:121-134. CrossRef Medline

Pond BB, Berglund K, Kuner T, Feng G, Augustine GJ, Schwartz-Bloom $\mathrm{RD}$ (2006) The chloride transporter $\mathrm{Na}(+)-\mathrm{K}(+)$-Cl- cotransporter isoform-1 contributes to intracellular chloride increases after in vitro ischemia. J Neurosci 26:1396-1406. CrossRef Medline

Qiu Z, Sylwestrak EL, Lieberman DN, Zhang Y, Liu XY, Ghosh A (2012) The Rett syndrome protein MeCP2 regulates synaptic scaling. J Neurosci 32: 989-994. CrossRef Medline

Reese AL, Kavalali ET (2015) Spontaneous neurotransmission signals through store-driven $\mathrm{Ca}$ transients to maintain synaptic homeostasis. eLife 4.

Rich MM, Wenner P (2007) Sensing and expressing homeostatic synaptic plasticity. Trends Neurosci 30:119-125. CrossRef Medline

Roufa D, Martonosi AN (1981) Effect of curare on the development of chicken embryo skeletal muscle in ovo. Biochem Pharmacol 30: 1501-1505. CrossRef Medline

Ruano-Gil D, Nardi-Vilardaga J, Tejedo-Mateu A (1978) Influence of extrinsic factors on the development of the articular system. Acta Anat (Basel) 101:36-44. CrossRef

Soden ME, Chen L (2010) Fragile X protein FMRP is required for homeostatic plasticity and regulation of synaptic strength by retinoic acid. J Neurosci 30:16910-16921. CrossRef Medline

Stellwagen D, Malenka RC (2006) Synaptic scaling mediated by glial TNFalpha. Nature 440:1054-1059. CrossRef Medline

Sutton MA, Ito HT, Cressy P, KempfC, Woo JC, Schuman EM (2006) Miniature neurotransmission stabilizes synaptic function via tonic suppres- 
sion of local dendritic protein synthesis. Cell 125:785-799. CrossRef Medline

Sweatt JD (2016) Dynamic DNA methylation controls glutamate receptor trafficking and synaptic scaling. J Neurochem 137:312-330. CrossRef Medline

Thiagarajan TC, Lindskog M, Tsien RW (2005) Adaptation to synaptic inactivity in hippocampal neurons. Neuron 47:725-737. CrossRef Medline

Turrigiano G (2011) Too many cooks? Intrinsic and synaptic homeostatic mechanisms in cortical circuit refinement. Annu Rev Neurosci 34:89103. CrossRef Medline

Turrigiano G (2012) Homeostatic synaptic plasticity: local and global mechanisms for stabilizing neuronal function. Cold Spring Harb Perspect Biol 4:a005736. CrossRef Medline

Turrigiano GG, Leslie KR, Desai NS, Rutherford LC, Nelson SB (1998) Activity-dependent scaling of quantal amplitude in neocortical neurons. Nature 391:892-896. CrossRef Medline

Wang HL, Zhang Z, Hintze M, Chen L (2011) Decrease in calcium concentration triggers neuronal retinoic acid synthesis during homeostatic synaptic plasticity. J Neurosci 31:17764-17771. CrossRef Medline

Webb CB, Cope TC (1992) Modulation of la EPSP amplitude: the effects of chronic synaptic inactivity. J Neurosci 12:338-344. Medline
Wenner P (2014) Homeostatic synaptic plasticity in developing spinal networks driven by excitatory GABAergic currents. Neuropharmacology 78: 55-62. CrossRef Medline

Whitt JL, Petrus E, Lee HK (2014) Experience-dependent homeostatic synaptic plasticity in neocortex. Neuropharmacology 78:45-54. CrossRef Medline

Wilhelm JC (2008) The GABAa receptor is a critical part of the sensing machinery that triggers homeostatic plasticity of synapti strength and intrinsic excitability.

Wilhelm JC, Wenner P (2008) GABAA transmission is a critical step in the process of triggering homeostatic increases in quantal amplitude. Proc Natl Acad Sci U S A 105:11412-11417. CrossRef Medline

Yu H, Su Y, Shin J, Zhong C, Guo JU, Weng YL, Gao F, Geschwind DH, Coppola G, Ming GL, Song H (2015) Tet3 regulates synaptic transmission and homeostatic plasticity via DNA oxidation and repair. Nat Neurosci 18:836-843. CrossRef Medline

Zhou HY, Chen SR, Chen H, Pan HL (2011) Functional plasticity of group II metabotropic glutamate receptors in regulating spinal excitatory and inhibitory synaptic input in neuropathic pain. J Pharmacol Exp Ther 336:254-264. CrossRef Medline 